Rev. Hist., $\mathrm{N}^{\circ} 27$, vol. 2, Julio-Diciembre: 2020: 175-209

ISSN 0717-8832

https://doi.org/10.29393/RH27-15GPDG10015

\title{
The Guggenheim process. Innovaciones y contrapuntos de un sistema técnico y de transporte en la industria del salitre en el Departamento de Tocopilla (Chile, 1926-1949)*
}

\author{
The Guggenheim process. Innovations and counterpoints of a technical and transport \\ system in the saltpeter industry in the Department of Tocopilla (Chile, 1926-1949)
}

Damir Galaz-Mandakovic Fernández: Orcid: https://orcid.org/0000-0003-0312-6672**

\section{RESUMEN:}

A través de diversas fuentes documentales y hemerográficas, se caracteriza y analiza el devenir de un nuevo sistema técnico y procedimental que significó la reinvención y la continuidad del ciclo de los nitratos en la zona del cantón El Toco: hablamos del Guggenheim process, sistema operativo desde 1926. Se describen las particularidades técnicas y los impactos del nuevo procedimiento minero en la pampa (María Elena), en el ferrocarril (FCTT) y en el puerto de los Guggenheim (Tocopilla). En ese tenor, queremos demostrar que el nuevo sistema y el ciclo minero que inaugura, que además de ser el exitoso resultado tecnológico, científico y logístico del enlace de dos tipos de minería (la del cobre en Chuquicamata y la del salitre en El Toco) bajo el alero de Guggenheim Brothers, que si bien extendió el ciclo de los nitratos y descentró la hegemonía productiva de la zona de Tarapacá y Antofagasta, además de aumentar la escala de producción y de obtener un mejor fertilizante, no pudo escapar a fuertes desfases técnicos, tecnológicos y operativos, particularmente en su sistema portuario, situación que constituyó la existencia dos tiempos tecnológicos dentro del propio entramado territorial que articuló entre la pampa y la costa.

Palabras claves: Salitre, sistema Guggenheim, ferrocarril, Tocopilla, El Toco.

\section{ABSTRACT:}

Through various documentary and hemerographic sources, the evolution of a new technical and procedural system that meant the reinvention and continuity of the nitrate cycle in the area of the El Toco canton is characterized and analyzed: we talk about the Guggenheim process, operating system since 1926. In this article, it is examined and described the technical characteristics and the impacts of the new mining procedure on the pampa (María Elena), on the railway (FCTT) and in the port of

\footnotetext{
* Este artículo es producto del proyecto FONDECYT №11180932: Chuquicamata, Cantón El Toco y Tocopilla bajo la impronta de los Guggenheim: sistemas técnicos, sociedad, conflictos y medioambiente en el desierto de Atacama (1915-2015).

** Profesor de Historia y Geografía (Universidad de Tarapacá), Magíster y Doctor en Antropología (Universidad Católica del Norte), Magíster en Ciencias Sociales (Universidad de Antofagasta) y Doctor en Historia (Université Rennes 2 - Université Bretagne Loire). Universidad Católica del Norte, Chile. Email: damirgalaz@gmail.com.
} 
Guggenheim (Tocopilla). We want to demonstrate that the new system and the mining cycle that it inaugurates, that in addition to being the successful technological, scientific and logistical result of the linking of two types of mining (that of copper in Chuquicamata and that of saltpeter in El Toco) under the eaves of the Guggenheim Brothers, which, although it extended the nitrate cycle and reduced the productive hegemony of the Tarapacá and Antofagasta area, in addition to increasing the production scale and obtaining a better fertilizer, it could not escape from strong technical lags, technological and operational, particularly in its port system, a situation that constituted the existence of two technological times within the territorial framework that was articulated between the pampas and the coast.

Keyword: nitrate, Guggenheim process, railway, Tocopilla, El Toco.

Recibido: diciembre 2019

Aceptado: agosto 2020

\section{Introducción}

La aparición de The Guggenheim Brothers en la industria del salitre en la década de 1920, estuvo inscrita en una escena de desmantelamientos de cientos de minas salitreras que operaban con el sistema Shanks ${ }^{1}$. Dichos desarmes de las inversiones e infraestructuras realizadas por empresarios chilenos, yugoslavos, británicos, alemanes, entre otros, fueron el efecto ineludible de la crisis económica estructural iniciada en los años previos a la I Guerra Mundial, particularmente por las consecuencias de la guerra de los Balcanes (1912-1913), lo que significó una crisis económica en los productores de cereales, conllevando además un elevado precio de los transportes marítimos ${ }^{2}$.

En esas circunstancias, hubo un frustrado intento por controlar la producción de salitre en cuanto a la regulación de las cantidades de producción, además de instalar la discusión sobre una nueva política tributaria ${ }^{3}$. No obstante, dichas instancias fracasaron, evidenciándose la completa desorganización y precariedad de la industria salitrera.

A dicho cuadro hubo que sumar la consolidación de la competencia al salitre chileno a través de otros fertilizantes, entre ellos el sulfato de amonio, la cianamida y el nitrato de cal $^{4}$. Al mismo tiempo, se atestiguaba la aparición de cientos de Plantas fijadoras de nitrógeno en Europa gracias a las aplicaciones experimentales que difundieron los científicos Carl Bosch y Fritz

\footnotetext{
${ }^{1}$ Sistema de lixiviación del caliche a altas temperaturas para obtener salitre. Fue un procedimiento desarrollado por el británico Santiago Humberstone en la década de 1870.

2 Basciani, A. 2014. "Los Balcanes: el avispero revisitado. Desde la crisis oriental de 1908 a la Primera Guerra Mundial", en Historia y Política № 32, pp. 105-127.

${ }^{3}$ González, Sergio. 2015. "Normalización de la crisis y posición estratégica empresarial durante la expansión de la economía del salitre" en Polis, Número 14, vol.40, Santiago, 397-419.

${ }^{4}$ González, Sergio, Calderón, Renato y Artaza, Pablo. 2016. "El fin del ciclo de expansión del salitre en Chile: la inflexión de 1919 como crisis estructural” en Revista de Historia Industrial, № 65, Vol. 25, , Barcelona, pp. 83- 110.
} 
Haber, galardonados con el Premio Nobel en Química en 1918, quienes patentaron el proceso llamado Haber-Bosch, caracterizado por la reacción de nitrógeno e hidrógeno sometido a altas presiones para producir gas amoníaco para abonos artificiales ${ }^{5}$. A su vez, en el desierto del norte de Chile se evidenciaba el agotamiento de los calichales de alta ley; las Plantas elaboradoras manifestaban igualmente las obsolescencias técnicas. En ese escenario, varias empresas estaban potencialmente en crisis por las deudas, además el mercado alemán estaba en fuerte decadencia ${ }^{6}$. Agréguese el periclitar de los capitales alemanes en la zona salitrera llamada El Toco, entre ellas la firma de Compañía Salitrera H.B. Sloman i Cía., que por efecto de figurar en las "listas negras" durante la guerra iniciada en 1914, vio fuertemente afectadas sus actividades por causa de sufrir los bloqueos navieros junto a la obstaculización del acceso a los combustibles. En definitiva, los mineros alemanes desplegados en Chile sufrieron la ofensiva de los capitales ingleses que imposibilitaron su funcionamiento ${ }^{7}$.

Las paralizaciones y los posteriores despoblamientos de las decenas de salitreras del sistema Shanks en la zona del cantón El Toco solo dejaron una espesa estela de cesantes ${ }^{8}$ y una huella material de la ruina y las múltiples acumulaciones de ripios que devinieron en la constitución de los archivos materiales que estructuraron una densa poética de la muerte y la vitalidad de una memoria productiva y social en el Desierto de Atacama9.

No obstante, en esa misma escena de estertores, desarmes, éxodos y fracasos de las expectativas, Guggenheim Brothers estaba apostando por un nuevo proyecto extractivista que vendría a transformar nuevamente el desierto y generaría una nueva "civilización" del habitar y del producir ${ }^{10}$. De ese modo, la simultaneidad de dos tipos de proyectos mineros, uno en

${ }^{5}$ Finck, Andre. 1988. Fertilizantes y fertilización: fundamentos y métodos para la fertilización de los cultivos. Barcelona, Editorial Reverté.

${ }^{6}$ Couyoumdjian, Ricardo. 1986. Chile y la Gran Bretaña durante la primera guerra mundial y la posguerra 1914-1921, Santiago, Editorial Andrés Bello y Ediciones de la Pontificia Universidad Católica de Chile.

7 Arce, Isaac. 1997 [1930]. Narraciones Históricas de Antofagasta, Antofagasta, Imprenta Moderna; GalazMandakovic, Damir. 2019. Movimientos, tensiones y luces. Historias tocopillanas, Tocopilla, Ediciones Bahía Algodonales.

8 Galaz-Mandakovic, Damir. 2013. Migración y biopolítica. Dos escenas del siglo XX tocopillano, Tocopilla, Retruécanos Ediciones.

${ }^{9}$ Respecto a la escena de crisis económica en la industria del salitre, conviene revisar el valioso trabajo sobre la zona sur de esta industria, particularmente con el caso del Departamento de Taltal por parte del historiador Milton Godoy Orellana, quien estudia la relación existente entre las dificultades económicas y los flujos migratorios en el periodo de auge y declinación de la producción salitrera, la cual, hacia los finales de la década de 1920, significó el desarme de 13 oficinas, la disminución de la población en la pampa y el repliegue de las líneas férreas. Dicho trabajo considera como hipótesis que el despoblamiento de la pampa salitrera fue un proceso de largo alcance, transcurriendo entre periodos intercensales con alcances intrarregionales e interregionales, donde los procesos de liquidación y captación de mano de obra operaron como un mecanismo regulador del flujo de obreros y sus familias. Ver: Godoy, Milton. 2019. “Minería, crisis económicas y flujos migratorios en Atacama meridional: Taltal (Chile), 1870-1950". Revista de Historia, № 26, vol.2, Concepción, 5-32.

10 González Pizarro, José Antonio. 2017. La épica del salitre en el desierto de Atacama, 1880-1967. Trabajo, tecnologías, vida cotidiana, conflicto y cultura, Antofagasta, Ediciones Universitarias, Universidad Católica del Norte. 
franca caída, y otro en contrario rumbo ascendente, marcaron un devenir singular en la década de 1920, especialmente en la zona conocida como el cantón salitrero de El Toco, en la actual Provincia de Tocopilla. Siguiendo a Schumpeter, este nuevo ciclo de la mano de los Guggenheim puede ser caracterizado como una "revolución" porque modificó "la estructura existente en la industria mediante la introducción de nuevos métodos de producción: la fábrica mecanizada, la electrificación, la síntesis química (...) con la ayuda de mercancías como los ferrocarriles (...) instrumentos eléctricos o con nuevas formas de organización como el movimiento de fusión de sociedades..."11.

En este artículo examinaremos, a través de diversas fuentes documentales y hemerográficas, el devenir del nuevo sistema técnico que significó la reinvención de la minería del salitre y por antonomasia, la extensión del ciclo de los nitratos, hablamos de Guggenheim process, operativo desde el año 1926.

Así, describiremos las particularidades técnicas que marcaron una diferencia substancial con el viejo sistema Shanks, el cual comenzó su declive desde 1919, analizando también la nueva articulación que surgió entre las nuevas Plantas salitreras, María Elena y Pedro de Valdivia con el puerto de Tocopilla, enfatizando en la innovación que existió en la tecnología de articulación mecánica y circulación de mercancías: la electrificación del Ferrocarril de Tocopilla al Toco (FCTT).

En ese tenor, queremos demostrar que el Guggenheim process y el ciclo minero que inaugura, además de ser el exitoso resultado tecnológico, científico y logístico del enlace de dos tipos de minería (la del cobre en Chuquicamata y la del salitre, en El Toco) bajo el alero de los mismos capitales, si bien extendió el ciclo de los nitratos y descentró la hegemonía productiva de la zona de Tarapacá y Antofagasta, además de aumentar la escala de producción y de obtener un mejor fertilizante, no pudo escapar a fuertes desfases técnicos, tecnológicos y operativos, particularmente en su sistema portuario, situación que constituyó la existencia dos tiempos tecnológicos dentro del propio entramado territorial que articuló entre la pampa y la costa el nuevo sistema de producción de salitre.

Entonces, esa idea de totalidad bajo la forma de orden que acontece normalmente sobre la memoria de los sistemas técnicos y sus ciclos asociados, en este caso queda deconstruida, porque daremos cuenta de un sistema que no es totalizador u homogéneo en su operación. Esto lo señalamos porque Tocopilla, donde estaba la termoeléctrica de los Guggenheim para energizar Chuquicamata desde 1915, devino también en el puerto para exteriorizar la nueva producción salitrera del consorcio estadounidense. En el mencionado puerto se atestiguaron importantes innovaciones en el transporte del salitre y sus logísticas de almacenamiento, pero

\footnotetext{
${ }^{11}$ Schumpeter, Joseph. 2010. ¿Puede sobrevivir el capitalismo? La destrucción creativa y el futuro de la economía global, Madrid, Ediciones Capitán Swing libros, p.59.
} 
incongruentemente el sistema de embarque del mismo salitre era a través de una metodología anacrónica, constituyendo al puerto como una periferia tecnológica por efecto de las presiones políticas, agencias obreras y crisis económica. Entre el puerto y en la pampa Guggenheim se evidenció una particular asimetría.

\section{El nuevo proyecto de la familia minera}

El proyecto extractivista de Guggenheim Brothers ${ }^{12}$ en el desierto chileno, tiene su antecedente técnico y corporativo en la industrialización de la mina de cobre de Chuquicamata, proyecto ejecutado por la empresa The Chile Exploration Company perteneciente a Daniel Guggenheim, empresa que fue creada el 11 de enero de 1912 en la ciudad de New Jersey Condado de Hudson $^{13}$. Para el funcionamiento de la mina de cobre, previamente hubo que instalar una gran termoeléctrica en el puerto de Tocopilla ${ }^{14}$, ciudad distante a 140 kilómetros del centro minero. Ambas instalaciones, la termoeléctrica y la mina, fueron inauguradas el 18 de mayo de 1915. La mina estilo open pit, marcó una ruptura con el antiguo método extractivo a través de túneles y pirquenes. Chuquicamata con Tocopilla quedaron conectados a través de 1.913 torres de alta tensión.

Aprovechando el éxito del proyecto cuprífero que generó significativas ganancias para el consorcio estadounidense, además de las diversas instalaciones y capital humano avanzado, el presidente del directorio, Daniel Guggenheim, decidió realizar un interesante enlace a hacia otro tipo de minería, esta vez hacia una minería no metálica. Dicho enlace fue a través de un sistema técnico que era innovador y exitoso en los procesos de lixiviación por electrolisis que habían sido aplicados en el refinamiento del cobre chuquicamatino, resultando así una importante innovación que superó los sistemas de concentración y fundición tradicionales que se habían aplicado en el desierto de Atacama. Ese mismo sistema fue trasladado a la industria del salitre.

Para dichos propósitos, la renombrada familia minera conformó una nueva compañía Ilamada Anglo Chilean Consolidated Nitrate Corporation (ACCNC), formada en los Estados

\footnotetext{
12 Desde la segunda mitad del siglo XIX, la familia Guggenheim se hizo conocida mundialmente por los grandes emprendimientos, especialmente en el área de la minería, en ese contexto creó la famosa compañía American Smelting and Refining Company. La reputación y la fortuna familiar, los llevó a ser unos de los principales financistas del arte moderno, luego del arte contemporáneo y también de la aviación. En ese escenario, fundaron los grandes museos y laboratorios aeronáuticos. En la misma década en que los Guggenheim invertían en la industria del salitre, sus otras inversiones estaban situadas en los diamantes de Angola, en el cobre de México, en el caucho del Congo, en el oro de Alaska, entre otros negocios mineros. Ver: R. Grimm, R. 2002. Notable American Philanthropists: Biographies of Giving and Volunteering, New York, Greenwood Publishing Group.

${ }^{13}$ O'brien, Thomas. 1989. "Rich beyond the Dreams of Avarice: The Guggenheim in Chile", in Business History Review, № 63, pp. 122-159.

14 Galaz-Mandakovic, Damir. 2017. "Turbinas y electricidad para la mina, lámparas a parafina para la población: crónica de una asimetría del capitalismo minero en Tocopilla (1914-1942)", en Estudios Atacameños № 54, San Pedro de Atacama, pp. 179-200.
} 
Unidos con un capital de 3.600.000 libras esterlinas ${ }^{15}$. Nuevamente la base de operaciones sería el Departamento de Tocopilla.

El interés de los hermanos Guggenheim en la industria salitrera fue comprensible en el marco que los nitratos representaron otra diversificación de productos para sus empresas mineras. Además, la familia Guggenheim consideraba que Chile contaba con cierta estabilidad política y que brindaba seguridad social, jurídica y política para las inversiones extranjeras ${ }^{16}$. Asimismo, la explotación del salitre representó una nueva oportunidad para "estar a la vanguardia de la renovación tecnológica de una industria y obtener los altos beneficios resultantes" 17 .

El nuevo proyecto de los hermanos Guggenheim implicó la adquisición de todos los bienes, las propiedades y las logísticas portuarias de la compañía inglesa The Anglo Chilean Nitrate and Railway, empresa que contaba con un ferrocarril (FCTT) que conectaba el cantón El Toco con el puerto tocopillano desde el año 1890.

El programa minero consideró la adquisición de vastos terrenos con caliche, especialmente en la zona del Salar de Miraje, adicionándose los terrenos de la Oficina salitrera Coya Norte, la que luego sería nombrada como Oficina salitrera María Elena ${ }^{18}$. Dichos terrenos tenían una extensión de 90 kilómetros cuadrados. Esta compra fue "en la suma de 3.346 .000 dólares" ${ }^{19}$. Según el informe de la Sociedad Nacional de Minera de Chile (SONAMI) de 1926, aquellos terrenos "contienen, de acuerdo con los cateos del Fisco, más de 5.600 .000 toneladas métricas de caliche (...) sin tomar en consideración grandes cantidades de caliche de menor ley (...) que se estiman en 2.000 .000 toneladas" ${ }^{20}$. La implementación de María Elena tuvo un costo de 28 millones de dólares ${ }^{21}$.

Este proceso de transferencias de bienes, terrenos y diversas instalaciones ocurrió desde el 24 de diciembre de 1924. Las propiedades de la compañía británica pasaron a poder del grupo norteamericano el 1 de enero de 1925. Al poco tiempo, los estadounidenses implementaron

\footnotetext{
15 McConnell, Donald. 1935. "The Chilean Nitrate Industry", in The Journal of Political Economy, Vol. 43, № 4, University of Chicago, pp.506-529.

${ }^{16}$ Whitbeck, R. 1931. "Chilean Nitrate and the Nitrogen Revolution", in Economic Geography, Vol. 7, № 3, pp. $273-$ 283.

17 O'brien, Thomas. 1989. "Rich beyond the Dreams of Avarice: The Guggenheim in Chile", in Business History Review, № 63, p.139.

${ }^{18} \mathrm{El} 22$ de noviembre de 1926 se iniciaron los nuevos trabajos con Guggenheim process en la Oficina Coya Norte. Al fallecer la esposa del autor intelectual de este nuevo procedimiento, el 3 de abril de 1927, la Oficina fue renombrada como María Elena desde el 18 de abril de 1927 en homenaje a Mary Ellen Condon, esposa del ingeniero Elias Anton Cappelen-Smith. El 6 de mayo de 1927: La empresa informó a la Gobernación Departamental de Tocopilla del cambio de nombre, fue entonces el 14 de mayo de 1927 cuando se oficializó el cambio.

${ }^{19}$ Gutiérrez, Eulogio. 1926. Chuquicamata, Tierra Rojas. Historia y monografía, Santiago, Editorial Nascimento, p.87. 20 SONAMI. 1926. "Los Guggenheim y la industria salitrera", en Boletín Minero de la Sociedad Nacional de Minería № 322, Santiago, p.185.

${ }^{21}$ Collao, Juan. 2001. Historia de Tocopilla (obra póstuma), Tocopilla. Ed. Corporación Juan Collao Cerda.
} 
una importante Planta mecánica que inauguraría el proceso que cambió el paradigma en la industria salitrera, surgiendo así dos innovadoras plantas de tratamiento y elaboración del salitre, ellas fueron las Oficinas salitreras de María Elena (inaugurada en 1926) y la Oficina Pedro de Valdivia (inaugurada en 1931).

Dichas plantas de tratamiento exigieron la implementación de un campamento que contaba, en el caso de María Elena, con 158 chalets para empleados y 946 casas para obreros con familias, adicionando las habitaciones llamadas ranchos destinadas para los obreros solteros, además de la implementación de servicios públicos, tales como hospital, correos y telégrafos, escuelas, pulpería, registro Civil, iglesia y espacios para la socialización de los trabajadores (estadios y plazas). Este proceso implicó el aumento de los flujos migratorios hacía la nueva urbe minera (ver gráfico 1). El diario La Nación señaló en 1935 sobre María Elena: "el capitalismo por si, puede resolver los problemas que se estima que solo el socialismo sería capaz de hacerlo" 22 . Dos años después, el mismo diario indicaba: "las condiciones de vida en estas oficinas superan en mucho a lo que hubieran podido desear los más exigentes lideres obreros de antaño, cuando luchaban por hacer la vida del obrero pampino más llevadera, más higiénica, más humana"23.

Gráfico 1: Evolución de la población de los Company town de María Elena y Pedro de Valdivia entre 1926 y 1952.

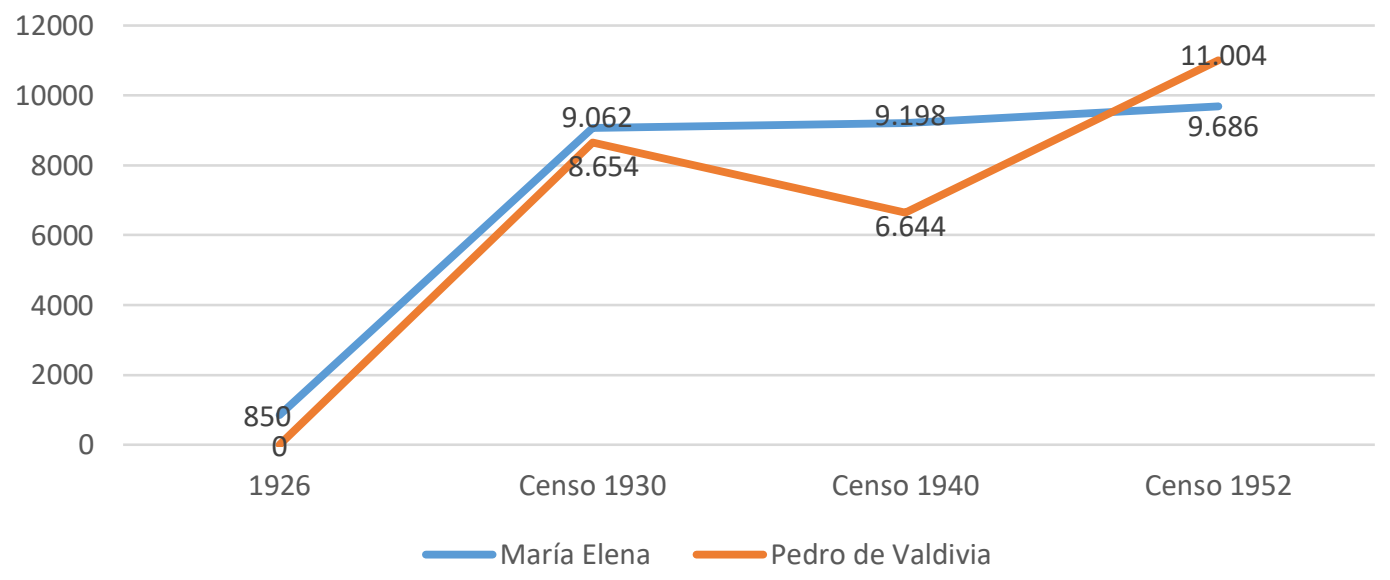

Fuente: elaboración propia a partir de a J. Collao (2001); los datos desde 1930 remite a los respectivos censos nacionales.

\footnotetext{
22 Archivo Universidad Diego Portales (AUDP), La Nación. Santiago, 11 de junio de 1935.

${ }^{23}$ AUDP, La Nación. Santiago, 1 de mayo de 1937.
} 


\section{El nuevo sistema técnico}

Sintéticamente, podemos indicar que las innovaciones técnicas del nuevo sistema fue una obra intelectual y científica del ingeniero químico noruego-estadounidense Elias Anton CappelenSmith, "considerado hoy como una de las cabezas organizadoras y directoras de grandes empresas industriales mundiales" 24 . La primera modificación sustancial de nuevo sistema fue dejar de realizar el rompimiento del terreno por medio de algunos tiros de dinamita o excavaciones manuales de cuevas, para luego ir "eligiendo a mano el material valioso, amontonándolo en sitios adecuados" 25 . Desde entonces, se introdujo la aplicación de cientos de tiros con detonadores eléctricos y pólvora negra de gran poder. El diario La Nación acotaba que, tanto en María Elena como en Pedro de Valdivia, el nuevo procedimiento implicaba que el caliche era extraído con:

"la pala mecánica, la formidable máquina con que hace 25 años se excavó el Canal de Panamá (...) No hay duda que los ingenieros norteamericanos tuvieron desde entonces fe profunda en la eficiencia de esta máquina, cuyo uso está hoy tan generalizado a toda excavación grande que deba hacerse al aire libre (...) en las salitreras, la naturaleza de la faena y del terreno obligan a usar la pala mecánica con mecanismo oruga de traslación" ${ }^{26}$.

Seguidamente, el material extraído era molido "a un tamaño de más o menos 1.0 centímetro. El 80-85\% del tonelaje de caliche reducido es depositado en grandes estanques de lixiviación" ${ }^{27}$. La referida lixiviación era posible a una menor temperatura: con agua a 40 C, es decir, mucho más fría que las aguas del sistema Shanks el cual realizaba una lixiviación a $70^{\circ} \mathrm{C}$ hasta los $105^{\circ} \mathrm{C}^{28}$, con una solución lixiviante compuesta de agua y salmuera ${ }^{29}$. Agua que después de circular por las partículas de caliche en los estanques y filtros, egresaba saturada en salitre sódico: aquella solución fuerte era llamada como el "caldo", el cual seguidamente era enfriado hasta los 15 으 con el objetivo que precipitara el excedente de salitre ${ }^{30}$. Con este

\footnotetext{
${ }^{24}$ Arce, I. 1997 [1930]. Narraciones Históricas de Antofagasta, Antofagasta, Imprenta Moderna, p.387.

${ }^{25}$ AUDP, La Nación. Santiago, 23 de diciembre de 1935.

${ }^{26}$ lbíd.

27 COVENSA. 1964. Agenda del salitre. Nitrato natural de Chile, Antofagasta, Editorial La Portada.p.101.

28 Soto, A. 1998. Influencia británica en el salitre. Origen, naturaleza y decadencia, Santiago, Editorial Universidad de Chile, p. 381.

${ }^{29}$ Garcés, Ingrid. (s/f) "Evolución de la tecnología de la industria salitrera: desde la olla del indio hasta nuestros días", Antofagasta, Facultad de Ingeniería Universidad de Antofagasta.

${ }^{30} \mathrm{El}$ aumento de las cantidades de aguas usadas por este nuevo sistema, significó un desabastecimiento hídrico que afectó fuertemente a las poblaciones de Antofagasta, Tocopilla, Calama, entre otras. Hacia los inicios de la década de 1930, el consumo mensual de agua para usos industriales y poblacionales en las nuevas Oficinas salitreras era de $140.000 \mathrm{~m} 3$, aguas obtenidas en las bocatomas de Lequena y Quinchamales junto al río Toconce. Mientras que en el mismo periodo la población de Tocopilla consumía $150 \mathrm{~m} 3$, por su parte Antofagasta recibía desde los principios el siglo XX 2.500m3, calculándose un déficit de $2000 \mathrm{~m} 3$ para la segunda mitad de la década de 1940. Ver: Arriaza,
} 
método, se aprovechaba de mejor modo el material de baja ley, facilitaba la concentración de las soluciones y cristalizaba los minerales por medio del enfriamiento a través de los compresores de amoniaco, formando cristales de tamaño suficientemente grandes que caían al fondo en una capa líquida formando una pulpa que decantaba en los espesadores Dorr para luego ir a las centrífugas ${ }^{31}$.

Para lograr la recuperación de yodo, la solución, el "caldo", era nuevamente calentado hasta los 40 ㄷ y comenzaba una recirculación. En esa situación, se consideraba que alrededor del $75 \%$ del nitrato era recuperado en ese circuito cerrado ${ }^{32}$.

Seguidamente, el nitrato cristalizado recibía un concluyente tratamiento en la Planta Granuladora donde era fundido en hornos de reverbero y luego era bombeado y enfriado con una fina irrigación. Consecutivamente, el producto se enfriaba al contacto con el aire y se convertía en nitrato granulado con una concentración del $94 \%$ al $98 \%$, "al solidificarse, el salitre toma una constitución granular que constituye una notable ventaja para su uso como abono" ${ }^{33}$. De ese modo, el nuevo sistema transformaba el salitre en perlas esféricas, marcando una gran diferencia con el salitre cristalizado del sistema Shanks ${ }^{34}$.

El nuevo salitre elaborado por los hermanos Guggenheim ayudó a superar un gran problema que existía con el salitre del sistema Shanks, el cual evidenciaba fuertes aglomeraciones de las partículas, generando densas encementaciones (endurecimiento) por causa de las impurezas que contenía y por la humedad que encontraba en los puertos y en los barcos. Esta situación hacía que los sacos salitreros engordaran en el viaje, provocando problemas en el pesaje y también en los obreros portuarios de Europa que tenían que descargar los pesados sacos amplificados y endurecidos por la humedad durante los largos trayectos.

Este inconveniente, según el ingeniero Emiliano López (1926), desapareció con el sistema de granulado de la etapa Guggenheim, ya que este sistema obtenía un $98 \%$ de cloruro de sodio, y las impurezas higrométricas estaban reducidas, situación que tornaba imposible la absorción de humedad existente en las canchas de almacenamiento en el puerto y posterior viaje. López detallaba en 1926: "Con esta última mejora, de transportar el salitre a granel, lo que se economice en sacos y obra de mano, evitando la ensacadura, será mas de $1 \mathrm{sh}$. por quintal

\footnotetext{
Bernardo y Galaz-Mandakovic, D. 2020. "Expansión minera, déficit hídrico y crisis sanitaria. La potabilización del río Toconce y el impacto del arsenicismo en la población de la Provincia de Antofagasta (1915-1971)", Historia 396, №1, Vol. 10, pp. 73-114.

${ }^{31}$ Csillaj, I. 2012. Oficinas María Elena y Pedro de Valdivia. El proceso industrial del salitre en el siglo XX, Santiago, Fundación Pro Cultura, Santiago, p.96.

32 CSAL (Compañía Salitrera Anglo Lautaro). 1955. El dilema de la industria salitrera: o se la reestructura de acuerdo con el referéndum de diciembre de 1954 o el salitre desaparece de la economía chilena, Santiago, Editorial Universo. ${ }^{33}$ AUDP, La Nación. Santiago, 23 de diciembre de 1935.

${ }^{34}$ CSAL. 1954. Guía general de materias y terminología salitrera, Santiago, Editorial Universo.
} 
métrico, además de lo mucho que se economizará en las distintas movilizaciones que tiene el salitre desde la cancha de las Oficinas hasta llegar al buque" 35 .

La circular №421 del Departamento de Agricultura de los Estados Unidos (1937) comentaba estas particularidades del nuevo proceso, señalando: "Probablemente, la mayor parte de la humedad en el nitrato del proceso Guggenheim se absorbe de la atmósfera después del proceso de fabricación. El contenido de cloro y potasio también es menor, pero el contenido de sodio es mucho mayor. El contenido total de nitrato, calculado como nitratos de sodio y potasio, varía de aproximadamente 98.3 a 98.8 por ciento" ${ }^{36}$.

Gráfico 2: Composición del salitre elaborado bajo el sistema Guggenheim.

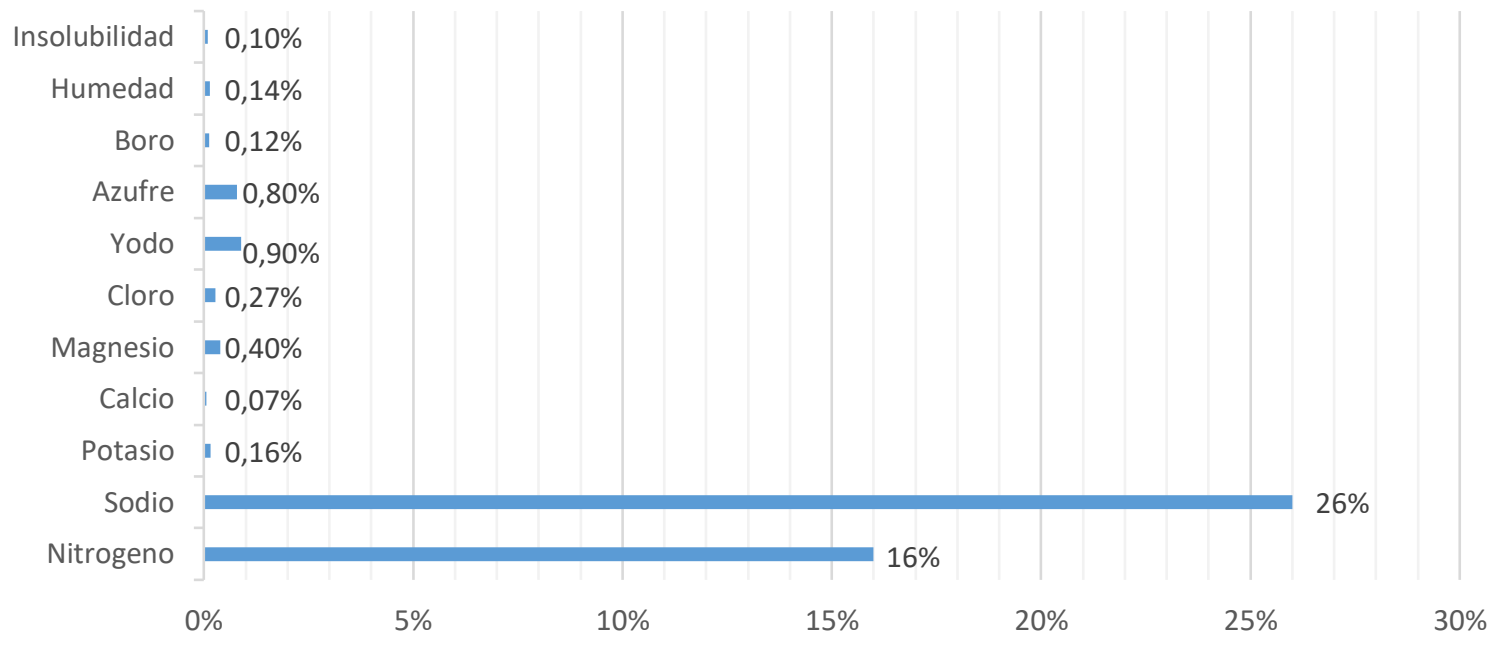

Elaboración propia. Fuente: United States Department of Agriculture (1937) Circular № 421.

Con base a varias muestras, el Departamento de Agricultura de los Estados Unidos de América (1937) indicó, promediadamente, que el nitrato de sodio estaba prácticamente libre de humedad (Gráfico 2), porque el contenido de agua era inferior al 0,05\%. Los elementos metálicos contenidos en ellos eran aproximadamente de $26.8 \%$ de sodio y menos de $0.1 \%$ de calcio y magnesio. Luego, los elementos no metálicos detectados eran alrededor del $16.3 \%$ de nitrógeno como nitrato, $0.15 \%$ de cloro como cloruro y $0.07 \%$ por ciento de azufre como sulfatos. La materia insoluble solía ser inferior al $0,1 \%$. El contenido total de nitrato, presente como nitrato de sodio, era aproximadamente del $98.8 \%$.

\footnotetext{
35 López, Emiliano. 1926. Los costos en la industria del salitre, Santiago, Imprenta y litografía Universo S.A, p.230.

${ }^{36}$ United States Department of Agriculture. 1937. Circular № 421. Washington, Government Printing Office, p. 559.
} 
Otros detalles diferenciales estaban remitidos a que en el producto cristalino del antiguo salitre del sistema Shanks, el nitrato de sodio podía variar de un color blanco puro a amarillo, rosado, gris, o incluso violeta. Los productos del Guggenheim process eran absolutamente blancos.

En pocas palabras, podemos decir que la innovación de los Guggenheim permitió obtener una mayor eficiencia química, necesitando a la vez menos hombres respecto a los procedimientos del sistema Shanks. En las salitreras del sistema Guggenheim (María Elena y Pedro de Valdivia) 7.000 hombres producían 70.000 toneladas de salitre. Mientras que las Plantas del sistema Shanks, 9.000 hombres producían tan solo 30.000 toneladas de salitre en promedio ${ }^{37}$.

De este modo, el sistema Guggenheim superó en sus cualidades electromecánicas, en sus singularidades técnicas y en el volumen de las instalaciones a una serie de experimentos realizados en las vastedades del desierto (Figura 1), tales como el sistema Allen, el Banthien, el Bellavista, el sistema Butters, el Iris, el Vidaurre, el Junquera, el Krupp, Matus, el Moscovia, el Nordenflycht, el Poupin, el Prache y Bouillon ${ }^{38}$, el San Gregorio, el Trent, el Delaware, el Duvieusart, el sistema Grillo-Perroni, el Prudhomme, entre otros ${ }^{39}$. Así, al emerger este procedimiento, se descentró la hegemonía productiva de Tarapacá con su sistema técnico predominante, el sistema Shanks ${ }^{40}$, el cual identificó "el predominio e influencia británica en la explotación del salitre, la aceptación del sistema Guggenheim tuvo un impacto destructor del control británico sobre estas actividades económicas" ${ }^{41}$.

Debemos entender que este proceso no solo tiene una dimensión técnica, sino que también social y por sobre todo política, en cuanto a las tensiones con grupos británicos que resistieron esta innovación, porque los Guggenheim proyectaban levantar un verdadero imperio en las salitreras, "que se basara en una compleja estructura legal y financiera, cuya base fueran las acciones, los bonos y la patente de utilización del sistema que propiciaban" ${ }^{42}$. En ese escenario, los antiguos salitreros "tuvieron que rendirse" 43 y asumir que el sistema Shanks iniciaba su declive definitivo. El político y militar socialista Marmaduque Grove denunciaba en el Senado

\footnotetext{
37 Soto, Alejandro. 1998. Influencia británica en el salitre. Origen, naturaleza y decadencia, Santiago, Editorial Universidad de Chile, p.633.

${ }^{38}$ Cuevas, Enrique. 1930. La industria salitrera y el salitre como abono, Berlín, Ediciones Buchdruckerei Silesia.

39 SONAMI. 1926. "Los Guggenheim y la industria salitrera", en Boletín Minero de la Sociedad Nacional de Minería № 322, Santiago, pp. 185-190.

${ }^{40}$ El sistema Guggenheim no significó el definitivo cese de las operaciones con sistema Shanks, ya que se atestiguan algunos casos de operaciones dispersas a través de algunos proyectos que quisieron resistir la crisis en desarrollo. El mejor ejemplo es la implementación de la Oficina Chacabuco, centro minero operativo desde el año 1924 bajo la administración de Anglo Nitrate Company Limited.

${ }^{41}$ Soto, Alejandro. 1998. Influencia británica en el salitre. Origen, naturaleza y decadencia, Santiago, Editorial Universidad de Chile, p.378.

42 Ibíd., p.390.

43 ibíd., p.379.
} 
de 1935: "jamás habrá acuerdo con las derechas, aquellas defienden un Chile para Guggenheim, mientras que la izquierda, un Chile para los chilenos" ${ }^{44}$. Esta denuncia evidenciaba las tensiones que surgieron ante la nueva hegemonía económica de los estadounidenses y su gravitación en las discusiones y decisiones políticas. Entonces, la inserción de los Guggenheim como nuevo actor, fue para muchos una erosión de la soberanía nacional, generándose, en el decir de historiador Carlos Donoso: "una distorsión mayor en la actividad, que obligaba, a quienes no pudiesen competir, a vender compulsivamente. Esto conduciría a la formación de un monopolio que reforzaría la dependencia fiscal” ${ }^{\prime 4}$.

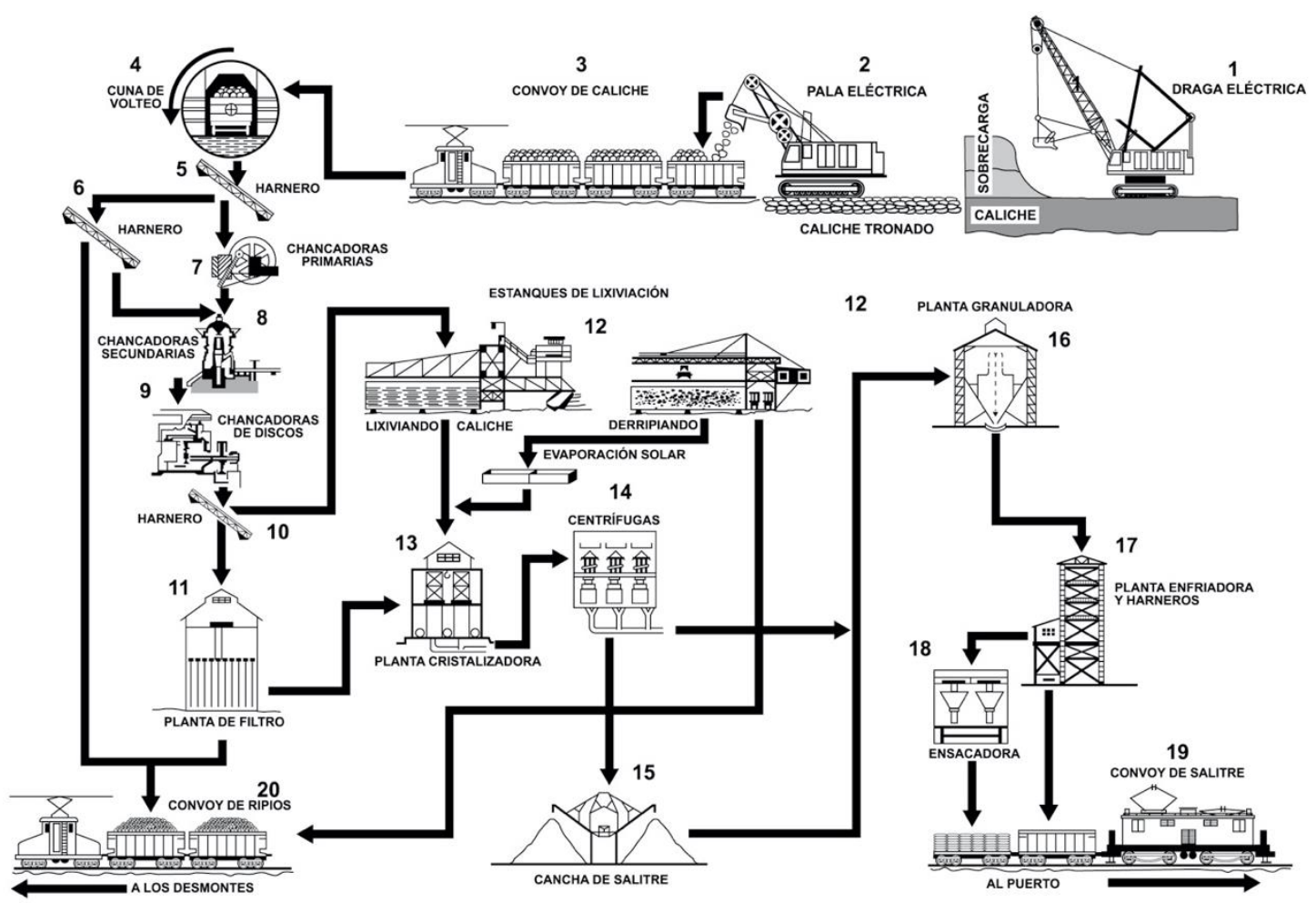

Figura 1: Los 20 procedimientos e instalaciones para la elaboración del salitre bajo el procedimiento Guggenheim. Fuente: elaboración propia basada en COVENSA (1964). Agenda del salitre. Nitrato natural de Chile. Edición gráfica: José Luis Aguirre Hidalgo.

Cerca de Elias Anton Cappelen-Smith estuvo el ingeniero formado en Massachusetts Institute of Technology, Stanley Freed, quien profundizó los estudios sobre los suelos de la pampa y a través de una investigación iniciada en el primer lustro de la década de 1930 y luego de seguidos ensayos, llegó a formular el Sistema de Evaporación Solar, la que comenzó a ser

\footnotetext{
${ }^{44}$ AUDP, La Nación. Santiago, 11 de junio de 1935.

45 Donoso, Carlos.2014. “El ocaso de la dependencia salitrera (1914-1926)”, en Diálogo Andino, № 45, Arica, p.115.
} 
construida en 1948, siendo inaugurada en 1951. Aquella innovación significó un importante ahorro en combustible. Al año siguiente, 1952, ya había 10 pozas de evaporación ${ }^{46}$. A su vez, Freed comenzó la investigación sobre los subproductos del salitre susceptibles de explotación comercial ${ }^{47}$. El proceso de evaporación solar permitió una ampliación del sistema Guggenheim porque se podía recuperar del caliche únicamente el nitrato de sodio y el yodo. Con una eficiencia del $75 \%$ para el nitrato de sodio, y un 35\% para el yodo. Fue así como el sistema de evaporación solar ayudó a recuperar una gran cantidad de sales y elementos del caliche con una alta eficacia, tales como el nitrato total, nitrato elemental, cloruro de sodio, sulfato de sodio, sulfato de calcio, sulfato de magnesio, borato de sodio, ácido bórico, perclorato de potasio, sulfato de lithium y yodo elemental ${ }^{48}$. De esta manera, se inauguró otra etapa.

\section{Modernización y electrificación del transporte del salitre}

Toda esta reinvención de la industria salitrera sería considerada insuficiente si acaso no era extendida al transporte del nuevo producto obtenido a través del innovador procedimiento realizado en la Oficina María Elena. Un hito técnico singular que transformaría los procesos de traslado y embarque del salitre, y que adicionó un significativo impacto urbano en la ciudad de Tocopilla, fue la electrificación del Ferrocarril de Tocopilla al Toco (FCTT).

El investigador lan Thomson indica que para impedir que los accionistas de Anglo Chilean Nitrate and Railway Company, dueños del Ferrocarril de Tocopilla al Toco, pudiesen internalizar para sí mismos las utilidades generadas por las dos nuevas y enormes Plantas, "los hermanos neoyorquinos decidieron simplemente comprar ese ferrocarril" ${ }^{49}$. De esa manera, el control de la zona, no solo en lo productivo, sino que también en la circulación de las personas, quedaba de lleno en manos de los Guggenheim.

Emiliano López (1926) al comentar estos procesos de innovación, enfatizó en la habilidad de los Guggenheim en cuanto a que generarían importantes ahorros en la relación de los trasladados de "cancha a puerto". El nuevo convoy y la adquisición de los terrenos en el puerto, apuntaba López, mejoraría el flujo de salitre en ese tráfico, porque "habrá de pasar de 330.000 a 1.000 .000 de toneladas al año ${ }^{50}$.

Para lograr aquellos propósitos, facilitar y mejorar el coste de explotación del ferrocarril y poder transportar un mayor tonelaje, la apuesta fue aprovechar la propia termoeléctrica de los

\footnotetext{
46 Arellano-Escudero, Nelson. 2018. "La energía solar industrial en el desierto de Atacama entre 1933 y 1952: investigación, desarrollo y sustentabilidad·, en Estudios Atacameños, № 57, San Pedro de Atacama, pp.119-140.

${ }^{47}$ García, Patricio. 2018. La reinvención de la industria del salitre, Santiago, Ediciones Memoria creativa.

48 COVENSA. 1964. Agenda del salitre. Nitrato natural de Chile, Antofagasta, Editorial La Portada, p. 105.

49 Thomson, lan. 2004. "La crisis económica y del salitre de principios del decenio 1930 y su impacto sobre los ferrocarriles", en Eco Pampino №22, p. 3.

50 López, Emiliano. 1926. Los costos en la industria del salitre, en Santiago, Imprenta y litografía Universo S.A., p. 229.
} 
Guggenheim y energizar el tramo más peligroso y pesado del ferrocarril salitrero. López agregaba: "Se tiene la intención de electrificar aquella sección del ferrocarril en que hay fuertes pendientes, y también construir un ramal de 30 millas, junto con adquirir el material rodante necesario y construir los desvíos, muelles y las otras mejoras necesarias en el puerto. El costo de estas mejoras se calcula en 2.700 .000 dólares" $^{\prime 51}$.

En esa dirección, el investigador indicaba que con la inversión de $\$ 22.000 .000$ de pesos surgiría una "economía importante" en los costos del transporte del salitre de la pampa al puerto y en los gastos de embarques Tocopilla; pues, no solamente se estaban introduciendo optimizaciones en las líneas férreas que atravesaban toda una cordillera costera con fuertes pendientes, sino que también se estaban proyectando importantes modificaciones en el puerto. Sobre esto último, López señalaba sobre el ferrocarril:

"Cuyo tráfico tiene que intensificarse porque están introduciendo también la importante mejora que solo había sido insinuada para el salitre en distintas ocasiones, de prepararse para el carguío a granel del salitre en carros especiales de bodega, el almacenamiento en la misma forma en Tocopilla y el transporte también a granel hasta el buque, en el que iría en la misma forma. Tal como se procede con el trigo y otros productos en otros países, empleando descargadores de succión apropiados" ${ }^{52}$.

En el año 1926 se autorizó la transferencia de la concesión del ferrocarril de Tocopilla al Toco con todas sus instalaciones, ramales y dependencias de Anglo Chilean Nitrate and Railway Company hacia The Anglo Chilean Consolideted Nitrate Corporation ${ }^{53}$.

Al año siguiente se autorizó a la termoeléctrica de The Chile Exploration Company para que proporcionara electricidad a Anglo Chilean Consolidated Nitrate Corporation. El decreto del Gobernador de la provincia, Tomás Lawrence, indicaba que la transferencia de electricidad era: "el sobrante de la fuerza eléctrica que la primera de las compañías nombradas genera en el puerto de Tocopilla, sin que esta autorización importe alteración del giro ordinario de sus operaciones" ${ }^{54}$. El 23 de julio de 1929, surgió la extensión de esta autorización: "por el término de 18 meses a contar del 6 del actual a través del Decreto № 1022 de 6 de abril de 1927 del ex Ministerio de Obras Publicas, Comercio y Vías de Comunicación a la Empresa Minera" ${ }^{55}$.

En ese escenario, desde en el año 1927 entró en funcionamiento la renovación sustantiva en el marco de la norteamericanización del capitalismo salitrero, llegaba el fin del ferrocarril a vapor que había sido inaugurado en 1890 por el presidente José Manuel Balmaceda. De este

\footnotetext{
51 Ibíd.p.229.

52 López, Emiliano. 1926. Los costos en la industria del salitre, Santiago, Imprenta y litografía Universo S.A., p. 229.

53 Archivo Gobernación de Tocopilla (AGT), Decreto Supremo № 565 del Ministerio de Obras Publicas, Comercio y Vías de Comunicación.

${ }^{54}$ AGT, Decreto Supremo № 1022, 6 de abril 1927.

${ }^{55}$ AGT, Decreto № 3086, 23 de julio de 1929.
} 
modo, la termoeléctrica de los Guggenheim volvió a inscribirse de manera importante en un nuevo ciclo que se inauguraba, esta vez, energizando el transporte del nuevo salitre hacia el puerto con las nuevas locomotoras que fueron fundadas en el condado de Schenectady en el Estado de Nueva York, siendo especialmente elaboradas para el ferrocarril tocopillano por la Compañía General Electric, forjando el reemplazo de las antiguas maquinarias a vapor KitsonMeyer del FCTT. Ese reemplazo fue relevante para cubrir el tramo más pesado entre el puerto y el Cantón El Toco. El cronista Juan Collao indicó que, de los 88 kilómetros de esta línea férrea, 27 iban por los cerros, y 61 por las pampas, agregando: "es una de las construcciones de ingeniería más atrevidas, por su enorme gradiente, sus curvas y sus cortes que atraviesan empinados cerros hasta tomar la planicie del Toco" ${ }^{56}$.

La electrificación fue una óptima decisión para avanzar con mayor seguridad en la gran pendiente determinada por las montañas. Además de querer acelerar el tráfico del convoy y mejorar su seguridad, la decisión de un nuevo ferrocarril tuvo que ver también con la carencia de agua de buena calidad para las máquinas a vapor y por el aumento del tráfico proyectado entre las nuevas Oficinas Guggenheim hacia el puerto tocopillano ${ }^{57}$.

Cabe señalar que la línea férrea había sido proyectada desde la llamada Estación Tocopilla, ubicada en el mismo puerto, en donde las líneas comunicaban a todos los muelles, con las bodegas y estanques de petróleo "de manera que toda la carga pueda embarcarse directamente hacia la pampa y el salitre y yodo desde la pampa al puerto para su exportación" ${ }^{\prime 5}$.

Desde aquel lugar, entonces, la línea atravesaba las verticalidades de la cordillera siguiendo el curso de la quebrada de Barriles, sorteando así decenas de curvas, algunas de hasta 55 metros de diámetro y con una gradiente máxima de 4,1\%, es decir cada 1 kilometro, la línea se elevaba 41 metros, en promedio. La altura máxima que alcanzó el trayecto ferroviario fue en la Estación Ojeda (ubicada en el kilómetro 54) alcanzando una altura de 1.495 m.s.n.m. Desde aquella estación iniciaba un lánguido descenso hasta la zona de El Toco y la Oficina Santa Isabel, ubicada en el kilómetro 88 de la ruta (Figura 2).

\footnotetext{
56 Collao, Juan. 2001. Historia de Tocopilla (obra póstuma), Tocopilla. Ed. Corporación Juan Collao Cerda, p.213. 57 Roney, Long. 1930. Railways of South America. Part III: Chile, Washington, Governenment printing office. ${ }^{58}$ Campdelacreu, Enrique. 2009. [1949] Tocopilla: una memoria de prueba, Tocopilla, Agrupación Cultural y Folclórica Tikopillan, p.165.
} 


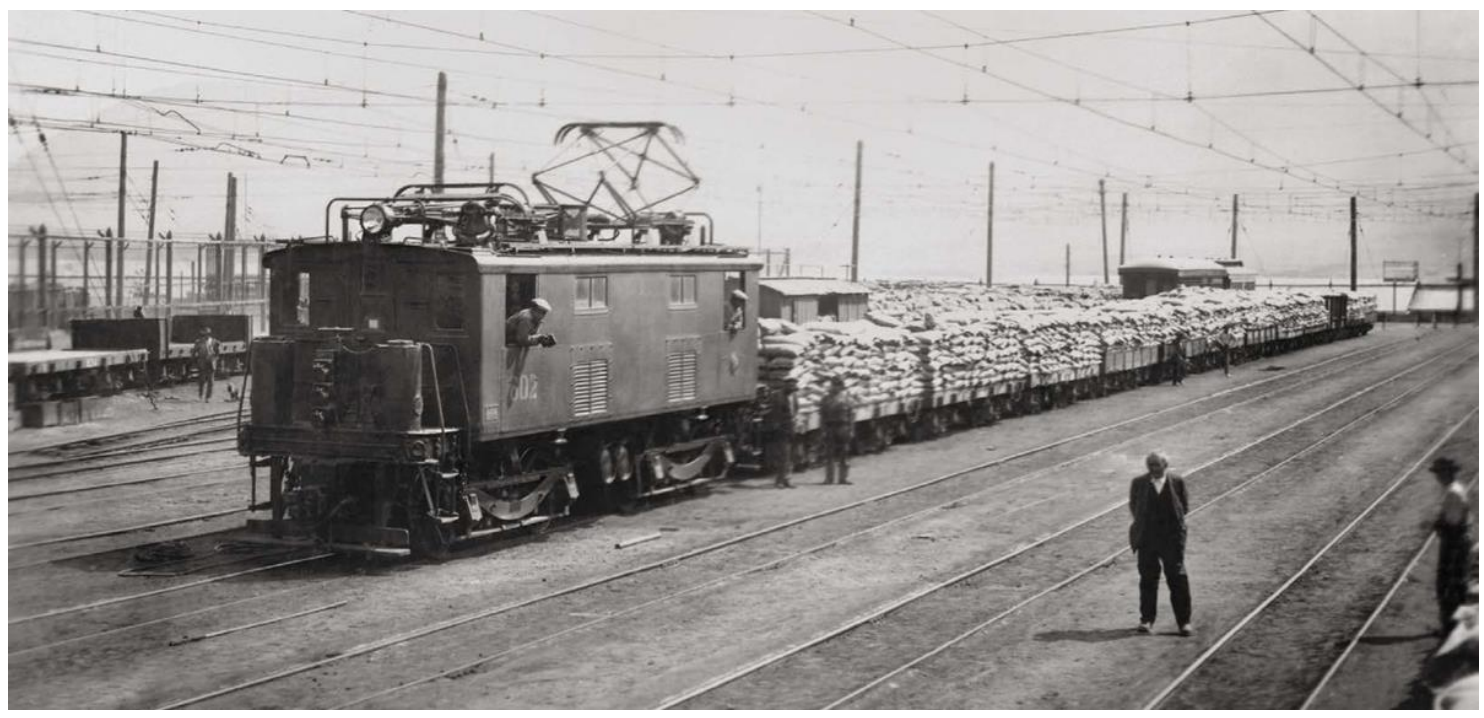

Figura 2: El ferrocarril eléctrico de los Guggenheim trasladando cientos de toneladas de salitre hacia el puerto de Tocopilla. Archivo D. Galaz-Mandakovic, s/f.

En ese marco de renovación, se autorizó a Anglo Chilean Consolideted Nitrate Corporation para construir un ramal con una trocha de 1.17 metros. La línea se extendió desde la estación El Tigre por un tramo de 45 kilómetros hasta empalmar con la naciente María Elena "una maravilla de la industria salitrera", puntualizó el testigo de la época el historiador Isaac Arce ${ }^{59}$. Los nuevos ramales dieron origen a nuevas estaciones, tales como Estación El Tigre, Estación Central, Colupito, Cerrillos, Tupiza y la propia estación de María Elena. La electrificación fue hasta la Estación El Tigre y el resto de la vía era "articulada por un convoy que funcionaba con locomotoras a diésel”60. (Ver figura 3).

\footnotetext{
${ }^{59}$ Arce, Isaac. 1997 [1930]. Narraciones Históricas de Antofagasta, Antofagasta, Imprenta Moderna, p. 388.

${ }^{60}$ AGT, Decreto $N^{\circ} 1645$ del 15 de julio de 1926.
} 


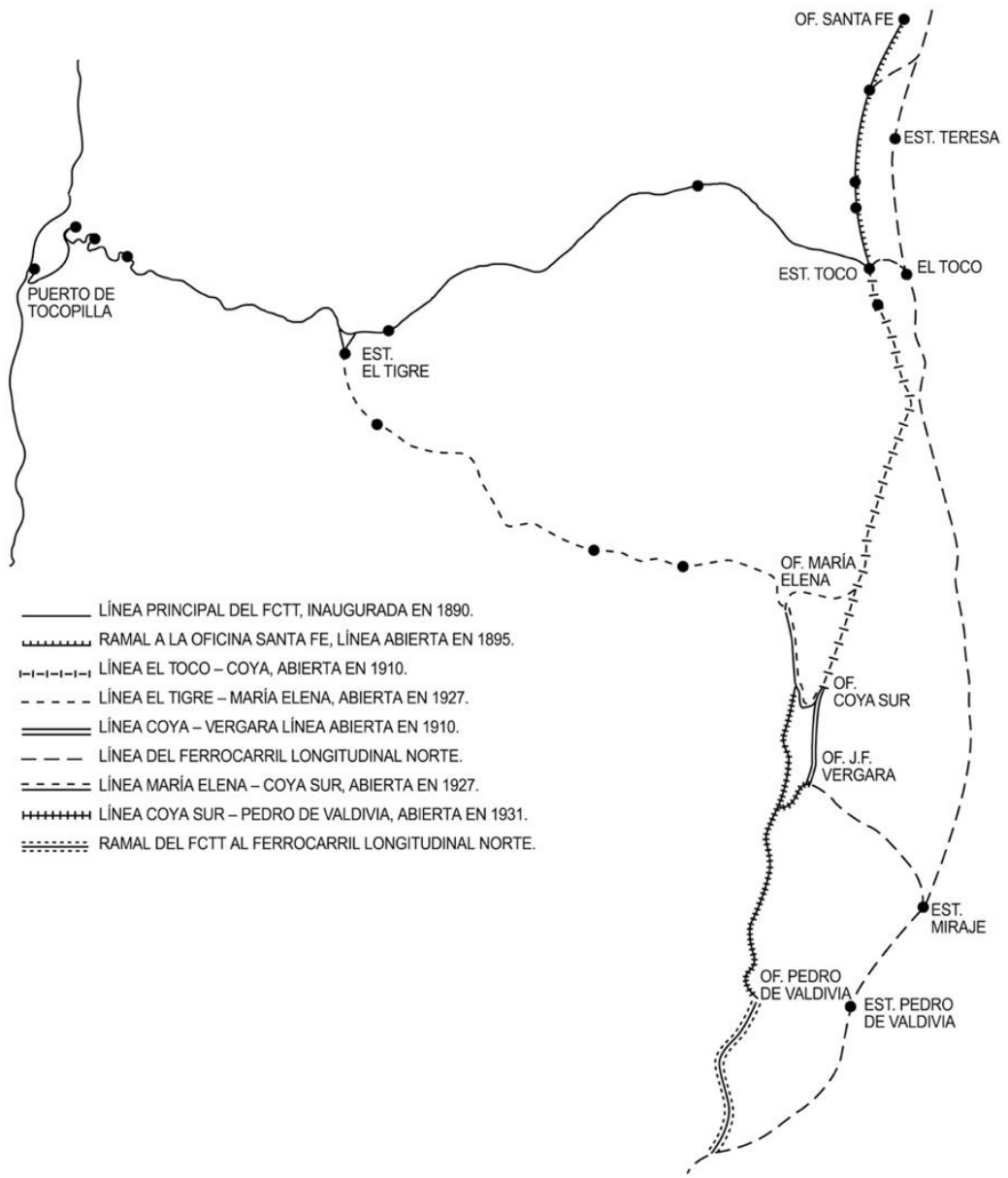

Figura 3: Ruta ferroviaria del Ferrocarril de Tocopilla al Toco que se inauguró en 1890, rumbo hacia las salitreras del sistema Shanks, bajo la impronta de capitales ingleses y alemanes. Del mismo modo, se indica el nuevo ramal que surgió desde la Estación El Tigre en el año 1927 dirigido hacia las Oficinas salitreras del sistema Guggenheim. Fuente: adaptación de D. Binns (1995). Edición gráfica: José Luis Aguirre Hidalgo.

Si contemplamos el perfil de la gradiente concerniente al tramo electrificado de la cordillera costeña, podemos considerar los siguientes datos en referencia al kilometraje de las estaciones de Tocopilla, kilómetro 0; Estación Reverso, kilómetro 7,1; Estación Carmelita kilómetro 12,23; Estación Quillagua, kilómetro 16,73; Estación Barriles, kilómetro 27,7; y Estación El Tigre distaba a 39,2 kilómetros desde el puerto. (Ver figura 4). 


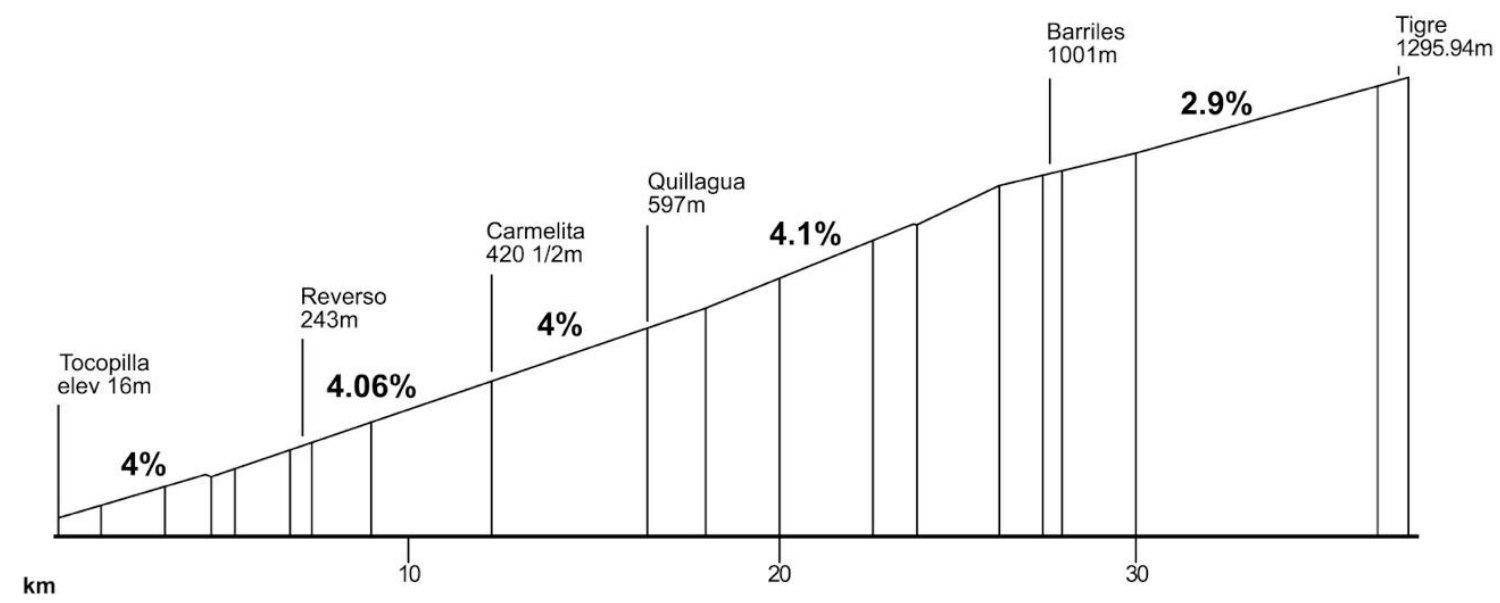

Figura 4: Perfil topográfico del tramo ferroviario electrificado por The Anglo Chilean Consolideted Nitrate Corporation en 1927, indicando el porcentaje de la gradiente de inclinación de la vía férrea. Fuente: D. Binns (1995). Elaboración y edición gráfica: José Luis Aguirre Hidalgo.

Para esta electrificación se solicitó la construcción de un total de siete locomotoras, cinco de ellas fueron construidas en el año 1927 y dos en 1928. Estas máquinas pesaban 60 toneladas y funcionaban con una potencia de 1.500 voltios de corriente continua. Asimismo, estaban equipadas con un sistema de frenado regenerativo, disponiendo de una potencia que les permitía alcanzar una velocidad de 28 kilómetros por hora ${ }^{61}$. (Ver tabla 1)

Tabla 1. Descripción de locomotoras eléctricas construidas en Schenectady, New York, por la compañía General Electric.

\begin{tabular}{|c|c|c|c|c|}
\hline $\begin{array}{c}\text { Denominación } \\
\text { corporativa }\end{array}$ & $\begin{array}{c}\text { Modelo de locomotora } \\
\text { eléctrica }\end{array}$ & № Construcción & $\begin{array}{c}\text { Año de } \\
\text { construcción }\end{array}$ & Peso \\
\hline 601 ACCNC & Bo-Bo General Electric & 10152 & 1927 & 60 toneladas \\
\hline 602 ACCNC & Bo-Bo General Electric & 10153 & 1927 & 60 toneladas \\
\hline 603 ACCNC & Bo-Bo General Electric & 10154 & 1927 & 60 toneladas \\
\hline 604 ACCNC & Bo-Bo General Electric & 10155 & 1927 & 60 toneladas \\
\hline 605 ACCNC & Bo-Bo General Electric & 10156 & 1927 & 60 toneladas \\
\hline 606 ACCNC & Bo-Bo General Electric & 10531 & 1928 & 60 toneladas \\
\hline 607 ACCNC & Bo-Bo General Electric & 10532 & 1928 & 60 toneladas \\
\hline
\end{tabular}

Fuente: Binns (1995).

61 Binns, Donald. 1995. The Anglo-Chilean Nitrate and Railway Company. A history of the Company and its locomotives, Yorkshire, Trackside Publications. 
En el año 1930 la línea férrea se amplió hacia el sur al comenzar la construcción de la Oficina Pedro de Valdivia, operativa a contar de 1931. De esa manera, la línea controlada por los Guggenheim alcanzó los 116 kilómetros, adicionándose nuevas combinaciones con el Ferrocarril Longitudinal en la estación Miraje, junto a Vergara, o en el Toco, frente a la Oficina Peregrina (Tabla 2).

Tabla 2: Nuevas estaciones ferroviarias que surgieron desde 1927 en el ramal iniciado en la Estación El Tigre hasta la Oficina Pedro de Valdivia.

\begin{tabular}{|c|c|c|}
\hline Estación ferroviaria & Altura $(\mathrm{msnm})$ & Distancia del puerto \\
\hline Colupito & 1.394 & 46,8 kilómetros \\
\hline Cerrillo & 1.375 & 61,0 kilómetros \\
\hline Tupiza & 1.282 & 75,4 kilómetros \\
\hline María Elena & 1.243 & 83,8 kilómetros \\
\hline Empalme Coya Sur & 1.263 & 91,2 kilómetros \\
\hline Cruce Vergara & 1.360 & 99,1 kilómetros \\
\hline Pedro de Valdivia & 1.455 & 115,7 kilómetros \\
\hline
\end{tabular}

Fuente: Ministerio de Transportes y Telecomunicaciones Subsecretaría de Transportes (2008).

Estos antecedentes, nos indican que el sistema Guggenheim sentaba un fuerte precedente tecnológico basado en la electricidad, porque este ciclo y sistema que vendría a significar la "metamorfosis de la industria"62 consumía "una cantidad superior de energía (...) debido en primer término a la mecanización de todas las operaciones" ${ }^{\prime 63}$, tales como la trituración fina en tres etapas, el harneo para la separación de los diferentes tamaños, movilización del sólido, carga y descarga de los estanques de lixiviación, incluyendo el movimiento y circulación de todos los líquidos, además de la cristalización mecánica, filtración a vacío de los finos, centrifugación de los cristales. Agréguese la obtención mecánica del frío artificial para efectuar la precipitación del salitre disuelto en líquido concentrado que provenía de la lixiviación: “EI consumo es de 50 a $60 \mathrm{KWH}$ efectivos por toneladas de caliche, lo que equivale tratando caliches de $12 \%$ con un rendimiento del $90 \%$ en la elaboración a un consumo de 250 a $300 \mathrm{KWH}$

62 Macuer, Horacio. 1930. Manual práctico de los trabajos en la pampa salitrera, Valparaíso, Talleres Gráficos Salesianos, p. 194.

63 SONAMI. 1926. "Los Guggenheim y la industria salitrera", en Boletín Minero de la Sociedad Nacional de Minería № 322, Santiago, p. 122. 
efectivos por tonelada de salitre producido" ${ }^{64}$. Así, la termoeléctrica en la ciudad de Tocopilla sustentaba dos regímenes mineros con sistemas técnicos enlazados, hegemonizados y patentados ${ }^{65}$ por una misma familia.

No obstante, este proceso de electrificación del ferrocarril salitrero de Tocopilla en el año 1927 despertó fuertes cuestionamientos políticos y populares hacia la usina eléctrica de The Chile Exploration Company por preferir electrificar a un tren y no electrificar a la ciudad de Tocopilla, la cual yacía completamente a oscuras y sin electricidad, evidenciándose una profunda paradoja de contar con una de las termoeléctricas más potentes de Sudamérica y a la vez tener una ciudad adyacente sin energía eléctrica ${ }^{66}$. Porque apenas instalada la termoeléctrica en 1915, los vecinos y autoridades intentaban convencer a los estadounidenses para electrificar la ciudad ${ }^{67}$, pero todo resultaba en vano ${ }^{68}$.

En ese escenario paradójico de ser Tocopilla una ciudad oscura y sin energía eléctrica urbana ni residencial, la alta potencia de la energía eléctrica de las empresas estadounidenses que operaban desde el mismo puerto, hizo que la extensión del ciclo del salitre adquiriera una fuerte densidad y una completa vigencia, manifestada en los altos volúmenes de producción de salitre y en los altos flujos navieros que estimuló, a saber que simultáneamente la zona de Tarapacá y Antofagasta vivían la decadencia profunda en la producción. Dicha situación de declinación productiva en la zona tarapaqueña y antofagastina, promovió el desmantelamiento de las plantas elaboradoras, entrañando también un vertiginoso despoblamiento de los campamentos de las salitreras del sistema Shanks ${ }^{69}$. La Comisión Aduanera de EE.UU., instancia que había estudiado la situación del mercado de los nitratos

\footnotetext{
${ }^{64}$ SONAMI. 1926. "Los Guggenheim y la industria salitrera", en Boletín Minero de la Sociedad Nacional de Minería № 322, Santiago, p.123.

65 Guggenheim process fue protegido en Chile a través de diversas patentes, entre ellas: patente № 4594, patente №4731, patente №4732, patente №5216. Todas ellas referidas a procedimientos de lixiviación, uso de sustancias estabilizantes, dispositivos de extracción y procedimientos de beneficio y percolación en la industria del salitre. CSAL. 1954. Guía general de materias y terminología salitrera, Santiago, Editorial Universo.

${ }^{66}$ Galaz-Mandakovic, Damir. 2019. Movimientos, tensiones y luces. Historias tocopillanas, Tocopilla, Ediciones Bahía Algodonales.

67 La ciudad pudo contar con electricidad e iluminación pública recién en 1942. Es decir, 28 años después de la inauguración de la termoeléctrica. De este modo, quedaba en evidencia una densa asimetría del capitalismo minero que no se interesó por contribuir al territorio y a la población en la cual estaba inserta.

${ }^{68}$ La Prensa de Tocopilla informaba en marzo de 1931 de la gran inversión que había realizado The Chile Exploration Company al invertir dos millones y medio de dólares en la compra a la Westinghouse Electric Company de tres locomotoras eléctricas de 77 toneladas y 600 caballos de fuerza cada una para Chuquicamata. "Pues, las seis locomotoras semejantes que adquirió en 1926 no se dan abasto en el transporte del mineral de cobre desde los yacimientos hasta las fabricas metalúrgicas". En ese escenario de electrificación, el diario sentenciaba: "la Chile Exploration Company ha llegado a ocupar prominentísimo lugar en la industria minera del mundo" (AGT, La Prensa de Tocopilla, 15 de marzo de 1931).

69 Entre 1924 y 1926 fueron clausuradas 31 Oficinas salitreras, mientras que los Guggenheim declaraban utilidades en igual periodo superiores a los 8 millones de dólares. Donoso, Carlos.2014. "El ocaso de la dependencia salitrera (1914-1926)" en Diálogo Andino, Arica, № 45, p.116.
} 
desde 1931 hasta 1937, indicó que la capacidad de competencia internacional de Chile había mejorado gracias a las nuevas Plantas de elaboración del sistema Guggenheim: "En Chile la erección de dos nuevas Plantas Guggenheim no aumentará considerablemente la capacidad nacional, pero es probable que haya prolongado por varios años la capacidad de ese país para competir eficazmente" ${ }^{71}$.

Al sumar diversos datos hallados en el archivo de la Gobernación de Tocopilla, podemos ver que desde 1926 a 1929 llegaron más de 739 barcos a Tocopilla, superando a los puertos de Antofagasta e lquique, puertos en los cuales hubo 448 y 391 naves respectivamente ${ }^{72}$.

En una muestra aleatoria, correspondiente a los meses de agosto, septiembre, octubre y noviembre de 1929, podemos revisar la siguiente cantidad de barcos que fueron registrados en Tocopilla para cargar salitre (Tabla 3).

Tabla 3: Cantidades de barcos y sus respectivas nacionalidades que llegaron a Tocopilla entre los meses de agosto y noviembre de 1929.

\begin{tabular}{|c|c|c|c|c|c|c|c|}
\hline \multicolumn{2}{|c|}{ Agosto 1929} & \multicolumn{2}{|c|}{ Septiembre 1929} & \multicolumn{2}{|c|}{ Octubre 1929} & \multicolumn{2}{|c|}{ Noviembre 1929} \\
\hline Nacionalidad & Cantidad & Nacionalidad & Cantidad & Nacionalidad & Cantidad & Nacionalidad & Cantidad \\
\hline Alemana & 5 & Alemana & 9 & Alemana & 6 & Alemana & 6 \\
\hline Británica & 9 & Británica & 9 & Británica & 4 & Británica & 6 \\
\hline Chilena & 44 & Chilena & 37 & Chilena & 31 & Chilena & 29 \\
\hline EE.UU. & 14 & EE.UU. & 14 & EE.UU. & 23 & EE.UU. & 24 \\
\hline Francés & 3 & Francés & 1 & Francés & 3 & Francés & 6 \\
\hline Griegos & 3 & Griegos & 1 & Griegos & 4 & Griegos & 3 \\
\hline Holandeses & 3 & Holandeses & 1 & Holandeses & 1 & Holandeses & 1 \\
\hline Italianos & 2 & Italianos & 2 & Italianos & 4 & Italianos & 4 \\
\hline Japonés & 1 & Japonés & 1 & Japonés & 1 & Japonés & 1 \\
\hline Noruega & 4 & Noruega & 4 & Noruega & 1 & Noruega & 2 \\
\hline Yugoslavos & 3 & Yugoslavos & 2 & Yugoslavos & 3 & Yugoslavos & 3 \\
\hline Españoles & 2 & Suecos & 3 & Suecos & 2 & Españoles & 2 \\
\hline $\begin{array}{c}\text { Total } \\
\text { mensual }\end{array}$ & 93 & $\begin{array}{c}\text { Total } \\
\text { mensual }\end{array}$ & 84 & $\begin{array}{c}\text { Total } \\
\text { mensual }\end{array}$ & 83 & $\begin{array}{c}\text { Total } \\
\text { mensual }\end{array}$ & 87 \\
\hline
\end{tabular}

Fuente: Archivo Gobernación de Tocopilla, reporte $s / n$ de actividades aduaneras en Tocopilla, 3 de diciembre de 1929.

Sobre la citada muestra aleatoria concerniente a tres meses de 1929 (Gráfico 3), podemos indicar que sobresalen los barcos de origen chileno (141), seguido por las naves

\footnotetext{
${ }^{71}$ AUDP, La Nación. Santiago, 22 de mayo de 1937.

72 Collao, Juan. 2001. Historia de Tocopilla.
} 
estadounidenses (75), luego los barcos británicos (28) y alemanes (26). Lamentablemente, dicha fuente no indica la capacidad de carga de cada nave.

Gráfico 3: Cantidad y país de origen de los barcos registrados en Tocopilla durante agosto, septiembre, octubre y noviembre de 1929.

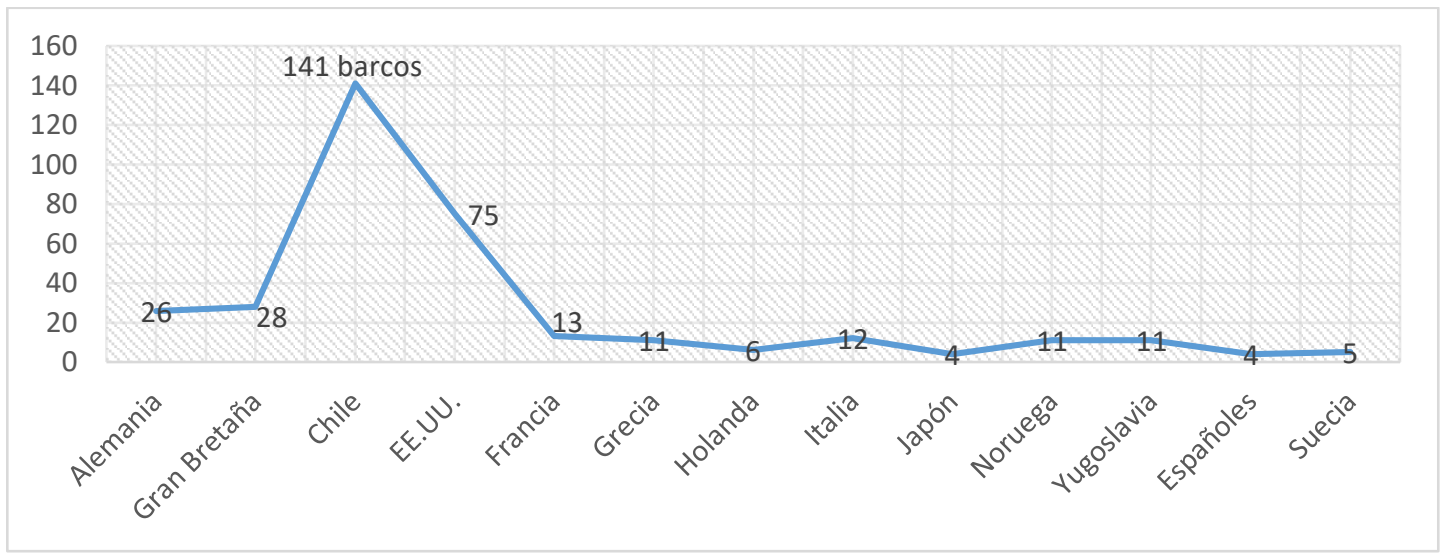

Elaboración propia basada en reporte $\mathrm{s} / \mathrm{n}$ de actividades aduaneras en Tocopilla, 3 de diciembre de 1929, Gobernación Departamental de Tocopilla.

En el año 1929 la exportación de salitre por Tocopilla alcanzó los 885.485 quintales métricos. Es decir, que la capacidad inicial de María Elena fue de 260.000 toneladas de salitre, procesando materiales con $7 \%$ de nitrato. Consecutivamente se amplió su capacidad a 500.000 toneladas anuales $^{73}$. Así, debemos adicionar la producción de la Oficina Pedro de Valdivia. Entonces, el ferrocarril eléctrico permitió el embarque de significativas cantidades de salitre por el puerto tocopillano entre los años 1934 y 1940 (Gráfico 4).

Podemos indicar con base a esos datos que el embarque fue paulatinamente aumentando, al punto que la producción del año salitrero 1934-1935 (612.661 toneladas) representaría solo el 58,8\% de lo que se exportó en el año 1939-1940 (1.023.911 toneladas). Si en el año 1914 la producción de 137 Oficinas Shanks distribuidas entre Tarapacá y Antofagasta embarcaron 1.846.000 toneladas ${ }^{74}$ cabe hacer notar que solo dos Oficinas Guggenheim permitieron el embarque de 1.023.911 toneladas en el año $1939^{75}$. Numerosos archivos fotográficos nos

\footnotetext{
${ }^{73}$ Collao, Juan. 2001. Historia de Tocopilla (obra póstuma). Tocopilla. Ed. Corporación Juan Collao Cerda.

74 Binns, Donald. 1995. The Anglo-Chilean Nitrate and Railway Company. A history of the Company and its locomotives. Yorkshire, Trackside Publications.

75 SONAMI. 1941. "Compañía Salitrera Anglo Chilena (ex Anglo Chilean Consolidate Nitrate Corporation)". En Boletín Minero de la Sociedad Nacional de Minería № 500, Santiago, pp. 1257-1258.
} 
retratan una bahía repleta de barcos, era el contraste total con los decadentes puertos salitreros de Pisagua, Iquique ${ }^{76}$, Antofagasta y Taltal.

Gráfico 4: Toneladas de salitre embarcadas en el puerto del sistema Guggenheim, Tocopilla, entre los años 1934 y 1940.

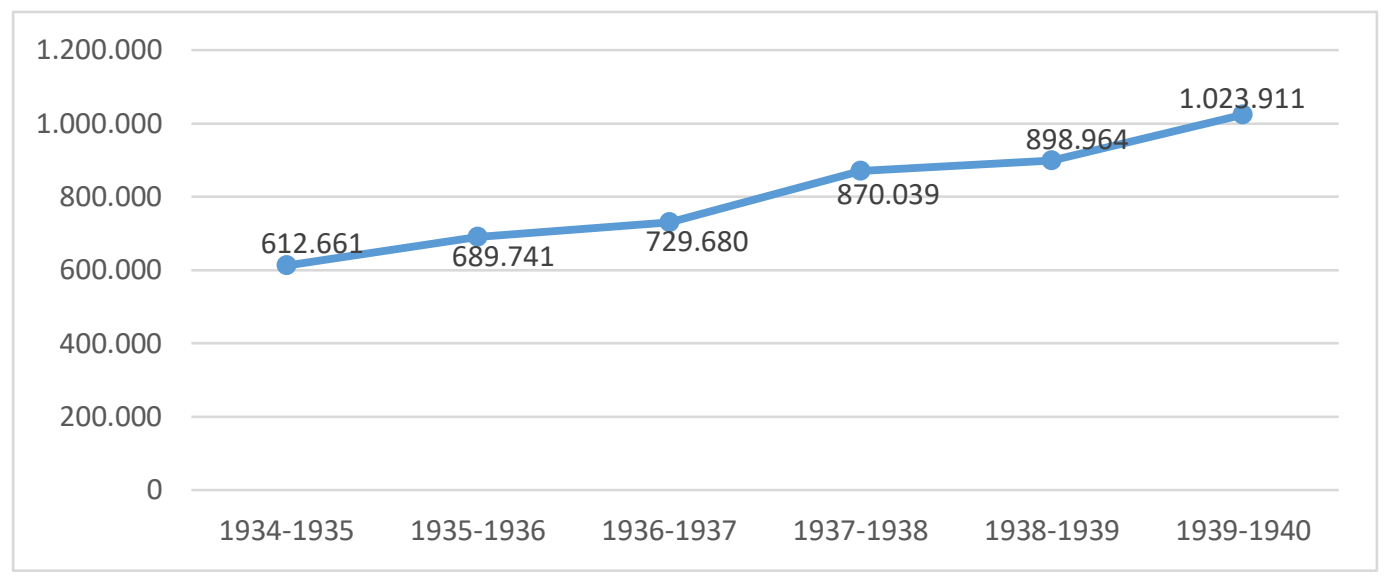

Fuente: Boletín mensual de la Sociedad Nacional de Minería (SONAMI), diciembre de 1941.

En el año 1941, SONAMI señalaba que María Elena se contaba con la presencia de 600 empleados y 3.600 obreros. En Tocopilla: 40 empleados y 500 obreros en el embarque, considerando además a 320 empleados en el ferrocarril y 1.420 obreros $^{80}$.

\section{Impacto urbano del ferrocarril Guggenheim en Tocopilla}

La electrificación del ferrocarril implicó la instalación de miles de postes de cedro americano que circundaron los cerros y diversas cuestas: las montañas costeras del desierto adquirieron una nueva estética. Las torres de alta tensión se dirigieron hacia la compañía salitrera que era contigua a la termoeléctrica. A su vez, hubo que instalar una serie de subestaciones eléctricas a lo largo del trayecto ferroviario para reforzar la energía que alimentaba las líneas. La corriente a 33.000 voltios debía transmitirse a dos subestaciones ubicadas en los kilómetros 4 y 33 de la línea férrea, facilitándose así la conversión a 1.500 voltios de corriente continua. Se adicionó un importante cambio de trocha para las nuevas máquinas ${ }^{81}$.

\footnotetext{
${ }^{76}$ La última salitrera en clausurar sus trabajos en la zona de Tarapacá fue la Oficina Victoria, la cual funcionaba con el sistema Shanks que había sido mejorado. Por su parte, en la zona de Antofagasta la Oficina Chacabuco había paralizado en 1944.

80 SONAMI. 1941. “Compañía Salitrera Anglo Chilena (ex Anglo Chilean Consolidate Nitrate Corporation)”. En Boletín Minero de la Sociedad Nacional de Minería № 500, Santiago, p. 1258.

${ }^{81}$ AGT, Oficio №32 a la Intendencia de Antofagasta, 3 de julio 1932.
} 
Una instalación llamativa fue la construcción de un puente ferroviario que facilitaba el acceso del convoy al puerto, el cual fue proyectado con una altura de 3 metros con 84 centímetros. Dicha pasarela de acero fundido con planchas remachadas fue erigida para superar los problemas de transitabilidad existentes en las zonas adyacentes a la termoeléctrica y al puerto salitrero: en la década de 1920 la ciudad enfrentaba el problema de la estrechez de los terrenos en las intersecciones barriales del Paseo Sloman, avenida que se ubicaba en la parte oriental de las compañías de los Guggenheim. Este estrechamiento estaba dado por el crecimiento sin control de la empresa salitrera que, una vez que el ferrocarril se electrificó, amplió sus instalaciones. Esto ocurrió porque llegaron nuevas máquinas, nuevos carros, hubo que establecer los tendidos eléctricos, implementar nuevas maestranzas y nuevos talleres mecánicos; además, se ensancharon varias bodegas y aumentó la producción de salitre por lo cual se necesitó una mayor cantidad de terrenos para depositar el nitrato y sus derivados. Igualmente, se tuvo que realizar el cambio de sentido de algunas calles, además de demoler algunas casas colindantes al puerto ${ }^{82}$.

Por ejemplo, el diario La Prensa de Tocopilla informaba el 11 de agosto 1928 que la compañía salitrera contaba con todos los "permisos necesarios para ampliar sus instalaciones ferroviarias", detallando que dentro de la ciudad se realizarían los siguientes cambios: "La longitud de las líneas de construcción inmediata es de 5 kilómetros y la longitud de las líneas de construcción posterior alcanza aproximadamente a 3 kilómetros".

Igualmente detallaba que varias calles serían intervenidas por el nuevo ferrocarril: "la concesión comprende el derecho para ocupar con vías férreas las siguientes calles de Tocopilla: calle Riquelme (entre Latorre y Prat); calle Bilbao (entre Riquelme y Balmaceda); y calle Balmaceda (entre Bilbao y Latorre)" 83 .

La amplificación de la intervención en el territorio por parte de los estadounidenses, se vio también relacionada con las ampliaciones de las casas de administración que colindaban con la compañía. Debemos apuntar que era un sector en donde la Cordillera de la Costa se acerca hacia el mar, existiendo voluminosos cerros y rocas. Todos estos factores restringían el paso de los ciudadanos, vehículos particulares y las carretas con tracción animal. A través de un angosto callejón se tenía que conectar la Villa Covadonga (el Company town de la termoeléctrica) y "El Pueblo" (el sector norte de la ciudad).

En ese sentido, la ciudad estaba fragmentada y prácticamente era un pequeño callejón la vía articuladora. Las esperas en esta calleja eran largas, al menos así lo constataban los primeros camiones de la compañía y las góndolas. Se culpaba a las compañías y la percepción local hacia las mismas se tornó de modo negativo. La compañía norteamericana solo había contribuido con

\footnotetext{
82 AGT, Correspondencia s/n de J. Colque, sobre "afectación de suelos..." 14 de enero 1929.

${ }^{83}$ AGT, La Prensa de Tocopilla, 11 de agosto 1928.
} 
algunos señaleros y serenos para que tratasen de dirigir el tránsito e intervenir las congestiones que generó el crecimiento de ambas empresas ${ }^{84}$.

Un dato interesante nos remite a cómo los Guggenheim fueron borrando diversos equipamientos de la ciudad, uno de ellos donado por el insigne industrial salitrero y filántropo alemán Henry Sloman. El diario La Prensa de Tocopilla indicó: "El industrial alemán don Henry Sloman obsequió a la ciudad, hace algunos años, una hermosa vereda que se extendía por ese paraje...constituyendo el único paseo de que podían disponer los tocopillanos para gozar de las delicias del aire del mar y la vista del hermoso paisaje que ofrecen en la tarde las rompientes de la costa, iluminadas por el sol poniente" ${ }^{85}$.

Todo el nuevo flujo, tanto de los primeros vehículos, como de carretas y el tráfico a pie que se generaría, no estaba planificado, fue por ello que Henry Sloman intentó contribuir a la ciudad porque el crecimiento y la ocupación de los espacios fueron prácticamente espontáneos sin intermediación del Estado. La ocupación de la Península de Algodonales fue gradual y netamente funcional con la industria de generación eléctrica y las actividades portuarias salitreras, sin velar ningún otro interés. Así, el Estado cedió su papel protagónico a empresarios y corporaciones privadas transnacionales que finalmente gestionaron el desarrollo territorial originando fraccionamientos, alteraciones, un impacto en el precio del suelo y el obstáculo del acceso al litoral.

La misma fuente periodística agrega: "cuando se construyó Villa Covadonga y se intensificó el tráfico de automóviles, la autoridad municipal no adoptó ninguna precaución para defender la vereda y, poco a poco, fue siendo invadida" 86 . Ese detalle trivial es a la vez una poderosa metáfora de la caída de un imperio de origen alemán y el auge del otro, de origen estadounidense. El segundo borró e invadió los terrenos del primero.

Como ya señalamos, vistos los problemas de congestión y peligrosidad para vehículos, carretas y caminantes, la compañía The Anglo Chilean Consolidated Nitrate Corporation decidió construir un puente para que pudiera transitar el ferrocarril electrificado, lo hizo dos años después: en 1929.

\footnotetext{
${ }^{84}$ AGT, La Prensa de Tocopilla, 15 de agosto de 1928.

${ }^{85}$ AGT, La Prensa de Tocopilla, 12 de septiembre 1928.

${ }^{86}$ AGT, La Prensa de Tocopilla, 12 de septiembre 1928.
} 
Para la construcción de aquel puente ${ }^{87}$ se tuvo que intervenir el "callejón" a través de un ensanche de seis metros. ${ }^{88}$ Los ingenieros fueron los señores H. W. Stoot y R. G. Street, ambos ingleses traídos especialmente por los Guggenheim a través del administrador del transporte ferroviario Carl Urbutt ${ }^{89}$. (Ver figura 5).

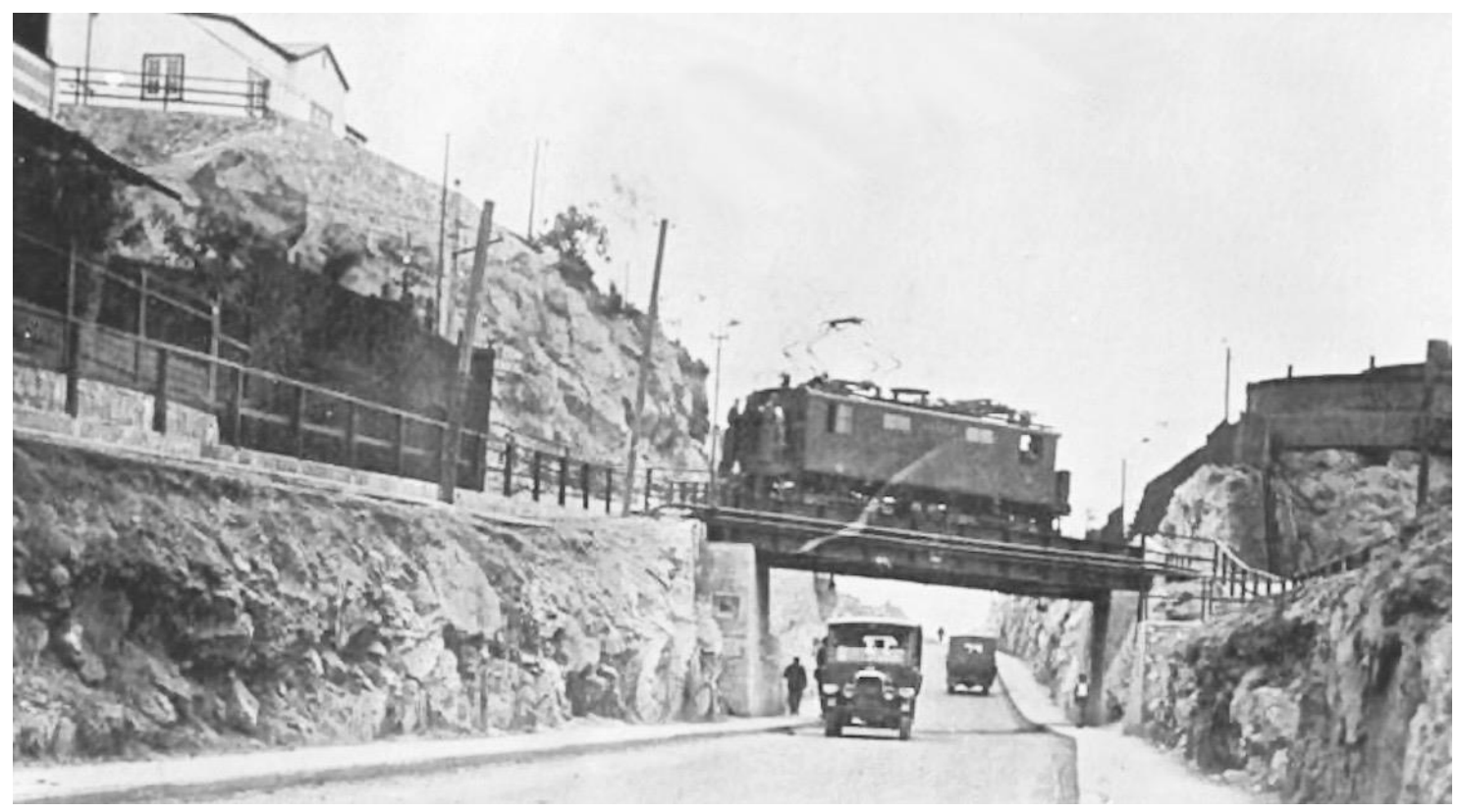

Figura 5: Puente ferroviario con una locomotora eléctrica, puente construido por los Guggenheim en el año 1929 en el sector conocido como Paseo Henry Sloman. Archivo del autor, circa 1930.

\footnotetext{
87 Un decreto del Ministerio de Fomento publicado en el Diario Oficial el 30 de junio de 1928, el cual fue reproducido por La Prensa de Tocopilla, indicaba que el Estado: "concedió a la Anglo Chilean Consolidate Nitrate Corporation el uso gratuito de las calles del barrio conocido con el nombre de Colonia Chilena". (AGT, La Prensa de Tocopilla, 11 de septiembre de 1928). Asimismo, dicho decreto indicaba las características del nuevo puente y la nueva calle que surgiría al instalarlo: "A) El paso bajo nivel constara de dos tramos de $4.10 \mathrm{~m}$. de luz cada uno, separado por un manchón de $60 \mathrm{~cm}$. de espesor. B) La altura libre bajo el puente será de $4.00 \mathrm{~m}$. C) La calzada bajo el puente será de $3.00 \mathrm{~m}$. de ancho y se dispondrán aceras de $0.80 \mathrm{~m}$. junto a los estribos y aceras de 0.50. m. junto al manchón". (AGT, La Prensa de Tocopilla, 11 de septiembre de 1928).

${ }^{88}$ Consecutivamente, iniciando la década de 1930, se realizaron algunas mejoras en el Paseo Sloman, tarea asumida por el Municipio, teniendo un costo de $\$ 119.000$. El paseo Sloman implicó además la construcción de un muro de concreto de 60 metros, al mismo tiempo, se construyeron calzadas y aceras con soleras de piedra en seco, todo un progreso vial con una mejora estética del sector (AGT, Copia de actas de Obras Municipales, № 121, 3 de febrero 1930.

${ }^{89}$ Rodney, L. 1930. Railways of South America. Part III: Chile, Washington, Governenment printing office.
} 


\section{Contrapunto portuario}

El diario La Nación señaló el 1 de mayo de 1937: "La compañía cuenta con propiedades en el puerto de Tocopilla, y con un moderno equipo marítimo para el embarque y desembarque de salitre y otros materiales y mercancías". Sin embargo, dichos comentarios estaban lejos de la realidad. Porque, si bien todo el devenir de modernización vivido en la pampa salitrera como así también en el transporte del salitre, demostraban que los procesos técnicos eran altamente costosos y resultaron ser una apuesta innovadora con base a una certeza científica y tecnológica. El sistema técnico implementado no abarcó la totalidad de este, sino que, por diversos factores, operó con ciertas asimetrías y diferentes tiempos tecnológicos. Esto lo afirmamos porque gran parte del sistema estaba electromecanizado, pero el puerto de embarque no vivió ninguna modificación.

El embarque del salitre siguió siendo prácticamente manual. He ahí una gran paradoja e incongruencia: en la pampa gran parte de la mano de obra había sido sustituida por las máquinas, enormes dragas recogían el material calichero después de la operación de los detonadores eléctricos con pólvora negra de gran poder, materiales que después eran depositados en un convoy eléctrico de rieles móviles, los procesos de lixiviación y cristalización que hemos descrito, fueron de una verdadera vanguardia. Luego, un gran ferrocarril con alta potencia eléctrica transportaba un salitre químicamente perfeccionado desde minas completamente modernizadas que evidenciaban un aumento en la escala productiva; finalmente, la producción llegaba a un muelle en donde esperaban cientos de trabajadores artesanales conocidos como obreros marítimos, quienes desplegaban sus propias fuerzas y disponían de su propio cuerpo semidesnudo para lograr el objetivo de exteriorizar la producción salitrera (Figuras 6 a 8). De este modo, el sistema técnico Guggenheim no logró inaugurarse en completitud, porque el puerto y sus obreros de despacho eran prácticamente los mismos que fueron instalados con el sistema Shanks desde los finales del siglo XIX. En ese cuadro, el puerto fue un espacio de resistencia técnica, era un contrapunto tecnológico sumamente asimétrico. En los hechos, la provincia de Tocopilla atestiguó la expresión de dos sistemas técnicos simultáneos en divergencia. 

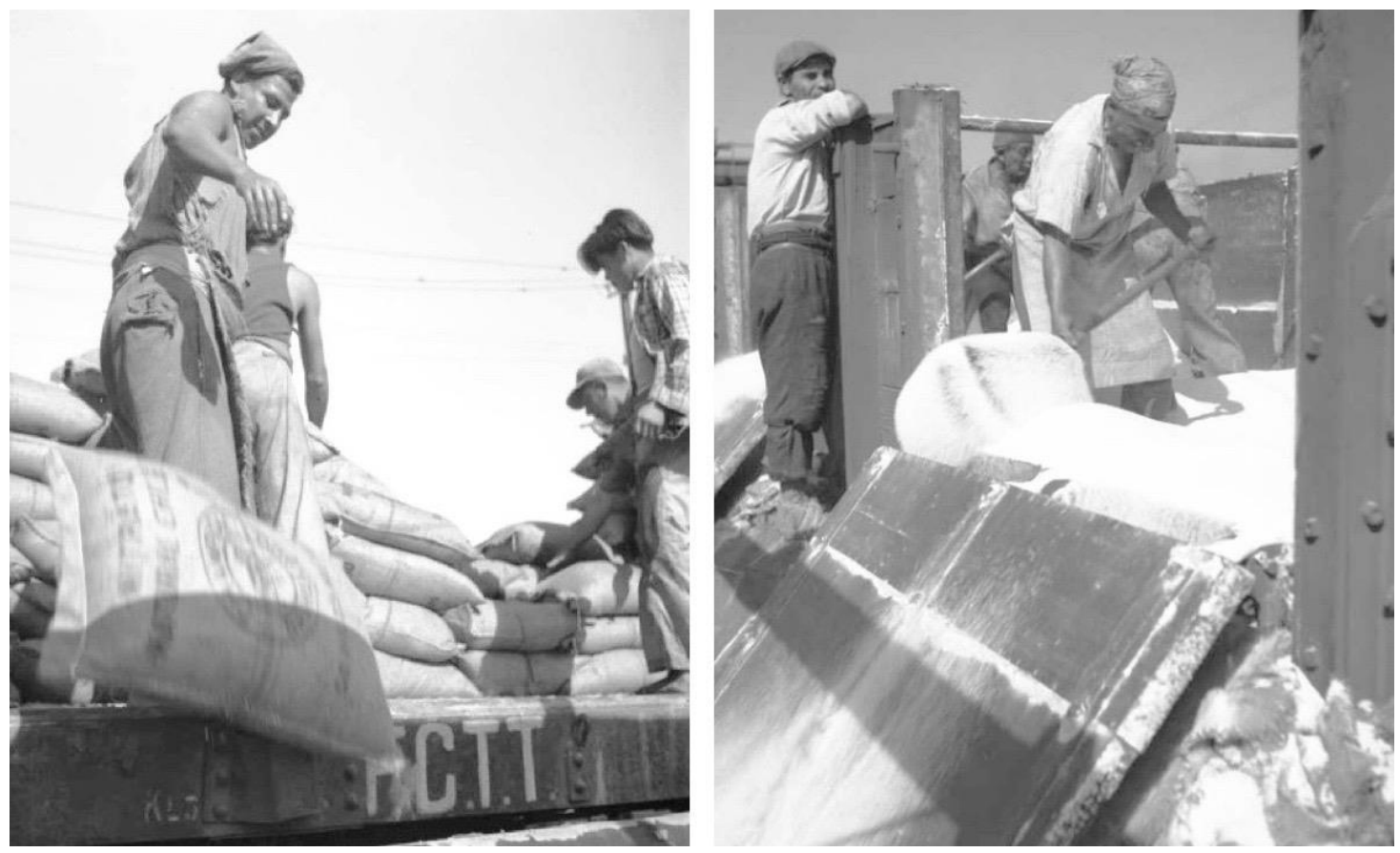

Figuras 6 y 7: A la izquierda: trabajadores portuarios que descargaban desde el carro de un ferrocarril los sacos con salitre para cargar más tarde las barcazas maulinas en dirección a los barcos. A la derecha: obrero portuario conocido como Jornalero de mar, quien realizaba la descarga del salitre no ensacado desde los carros del ferrocarril. Archivo del autor, $s / f$.

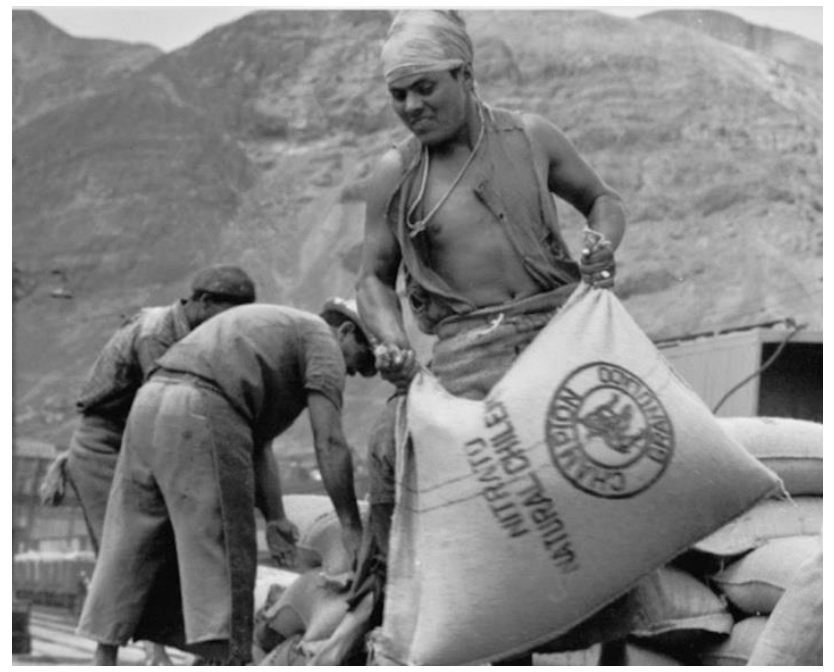

Figura 8: A saber de todas las electromecanizaciones acontecidas en las Plantas de elaboración de María Elena y Pedro de Valdivia, además de la electrificación y aumento de la capacidad de cargar del ferrocarril, en el puerto de los Guggenheim, la fuerza manual de los trabajadores era fundamental para embarcar el salitre, dicha situación, 
además de ser un fuerte contrapunto tecnológico, era una forma de trabajo con fuerte peligrosidad y vulnerabilidad laboral.

El nuevo sistema técnico y la nueva impronta estadounidense que destacaba por sus innovaciones químicas, mecánicas, eléctricas y habitacionales, naturalmente despertó los temores de estos obreros, esencialmente por las posibilidades de implementar algunas innovaciones mecánicas en el embarque del salitre, lo que encarnaría, en los hechos, el aumento de la cesantía. Era sabido que el nuevo sistema desestimaba la mano de obra de los hombres. Estos temores se amplificaron en circunstancias del aumento de la cesantía por el cierre de las salitreras del Cantón El Toco, "con lo cual treinta mil trabajadores perdieron sus puestos $^{\prime \prime 0}$. En ese devenir, siguiendo a G. Simondon, la nueva oleada tecnológica se caracterizaba por la ambivalencia del progreso, "por la doble situación del hombre en relación con la máquina y por la producción de alienación" ${ }^{91}$ En el marco de esa ambigüedad del progreso, el problema era la discontinuidad de los individuos.

Los obreros eran numerosos y representaban una importante diversidad de labores. Un documento fechado en abril de 1929 por la Gobernación Departamental de Tocopilla, en correspondencia con la Subdelegación Marítima de Tocopilla ${ }^{92}$ señalaba el listado de dichos obreros en el marco de una reunión que estos habían realizado. Lo interesante de dicha documentación es que indica los tipos de oficios relacionados con el embarque del salitre, dando un total de 30; asimismo indica la cantidad de trabajadores, llegando a un total de 697 personas (Gráfico 5). Esta gran cantidad de trabajadores portuarios comenzó a presionar para que la empresa no mecanizara las faenas. Así, había trabajo y se sustentaba la economía local.

Ante la reproducción de rumores y tensiones laborales, el diario La Prensa de Tocopilla señaló el 30 de octubre de 1931: "No hay tal mecanización de los embarques salitreros". Seguidamente, agregaba: "La Compañía Salitrera no implementará este sistema. Por el contrario, después de hacer experimentaciones (...) en vista de la abundancia de brazos, resolvió, considerando la crisis de trabajo, seguir con su acostumbrado sistema de embarque" ${ }^{\prime 33}$. Un informe del Inspector del Trabajo indicaba: "Preocupada esta repartición del asunto de los medios mecánicos para el embarque del salitre a granel (...) el infrascrito se entrevistó con los gerentes y jefes de la Compañía quienes (...) no lo implantarán mientras dure la crisis que nos aqueja, al contrario, dijeron, tratarán de darle trabajo a un mayor número de obreros" ${ }^{\prime 94}$.

\footnotetext{
90 Rinke, Stefan. 2002. Cultura de masas: reforma y nacionalismo en Chile 1910-1931, Santiago, Eds. de la Dirección de Bibliotecas, Archivos y Museos, Centro de Investigaciones Diego Barros Arana, p. 155.

${ }^{91}$ Simondon, Gilbert. 2007. El modo de existencia de los objetos técnicos, Buenos Aires, Editorial Prometeo Libros, p.135.

92 AGT, Correspondencia №23 entre la Subdelegación Marítima y Gobernación, 23 de abril de 1929.

${ }^{93}$ AGT, La Prensa de Tocopilla, 30 de octubre de 1931.

${ }^{94}$ AGT, Inspección del Trabajo, doc. № 1306 al Sr. Gobernador, 28 de octubre de 1931.
} 
Gráfico 5: Listado de obreros portuarios en el muelle de exportación de la producción Guggenheim.

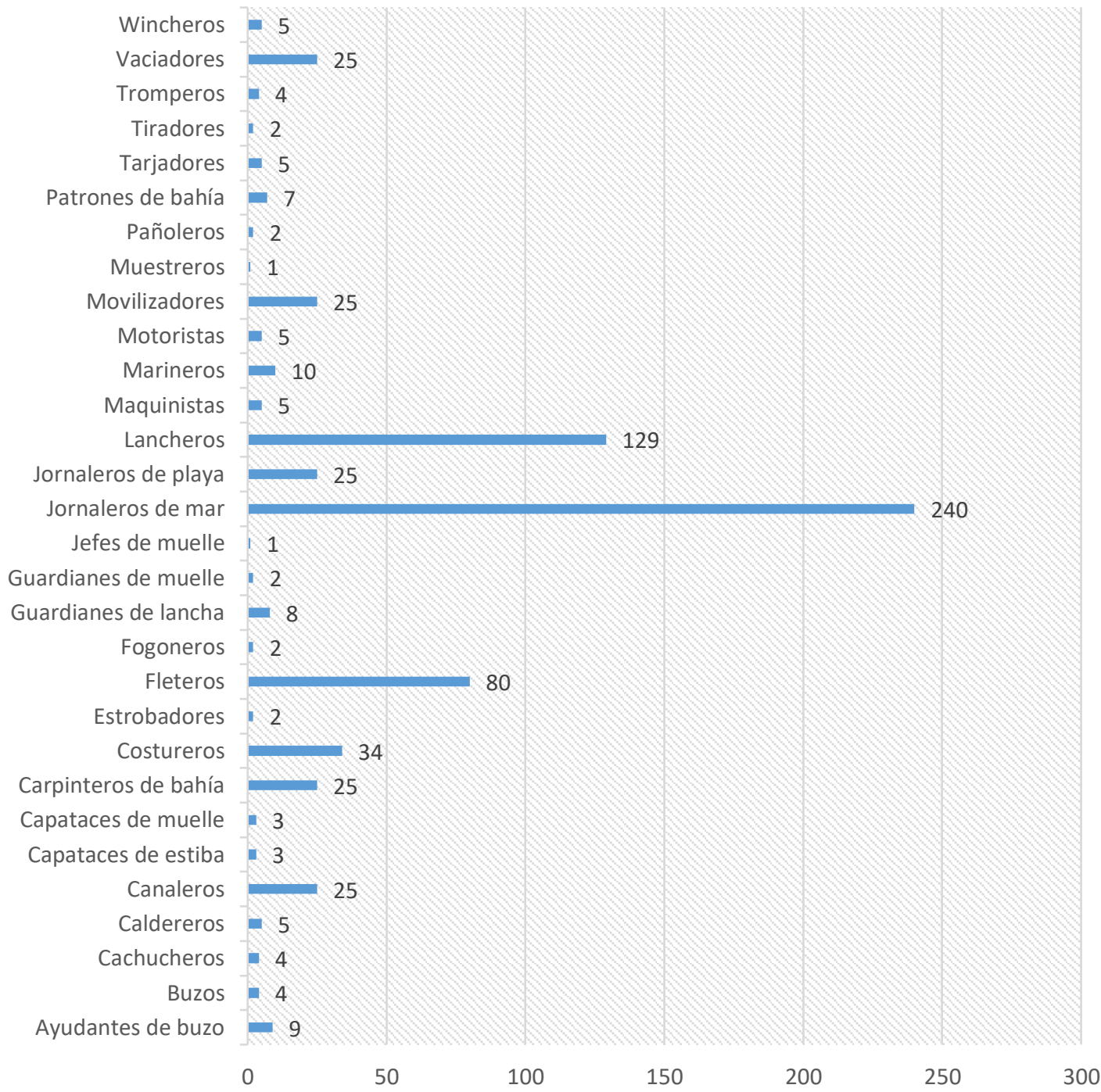

Archivo Gobernación de Tocopilla, correspondencia №23 entre la Subdelegación Marítima y Gobernación Departamental de Tocopilla, 23 de abril de 1929.

Definitivamente, ante la presión de las autoridades regionales y del Comité Pro Defensa de Tocopilla se logró convencer a los administradores de la compañía salitrera para mantener un sistema prácticamente manual de embarque; además, las amenazas de los portuarios de paralizar completamente el embarque a granel también impulsaron la suspensión del proyecto 
electromecanizador que era muy impopular ${ }^{97}$, a saber de la anacronía del puerto y los altos costos que para la compañía significaba la lentitud del embarque y la caída de salitre al mar, a saber de alta peligrosidad laboral que redundada en varios accidentes con heridos y muertos dentro de la gran cantidad de operarios portuarios que accionaban la carga con faluchos maulinos y lanchones de acero empujados por algunos remolcadores. Aún así, el miedo a las máquinas se fue densificando como fantasma constante en el imaginario local, mucho más en el fragor de la gran crisis iniciada en $1929^{98}$.

Sobre dicha presión obrera, cabe indicar que esta fue efectiva porque estaba latente el recuerdo del boicot y bloqueo portuario que realizaron los obreros marítimos en 1923, momento en que pertenecía a The Anglo Chilean Nitrate and Railway, quienes en apoyo y en articulación de fuerzas con los obreros en huelga de The Chile Exploration pusieron en jaque la producción de electricidad y por tal razón la producción de cobre refinado en Chuquicamata al no permitir el desembarco de diversos materiales y repuestos enviados desde el extranjero hacia la termoeléctrica, como así también la suspensión integral de la labores, quedando solo la opción que los militares y policías reemplazaran a los obreros en huelga ${ }^{99}$. Todas estas agencias y protestas fueron articuladas a través de la Gremial de Trabajadores Mar y Tierra, constituida el 23 de enero de 1922, alianza estratégica que contó con el respaldo de la Federación Obrera de Chile.

Dicha alianza de obreros interempresa, fue la mancomunión de fuerzas importantes en su dimensión política, asociativa, en volumen de operarios y en el poderío que adquirirían al bloquear o paralizar las actividades más importantes del poblado. De esta forma, los obreros portuarios y termoeléctricos modularon una potencia que buscó instaurar cierta simetría negociadora con las respectivas jefaturas y representantes de los Guggenheim desde el primer lustro de la década de 1920.

Esas memorias de articulación obrera cercana a la mecanización integral de los Guggenheim, fueron traídas a colación para tensionar la imagen que los norteamericanos habían difundido en la localidad, en cuanto a que la tecnologización era el único camino en la industria del salitre y así obtener la rentabilidad en desmedro de la fuerza política de los trabajadores. Un oficio confidencial del Gobernador Lindorfo Alarcón al Inspector del Trabajo señalaba: "Es recomendable la no mecanización del embarque del salitre en Tocopilla porque los obreros

\footnotetext{
${ }_{97}$ AGT, La Prensa de Tocopilla, 12 de noviembre de 1931.

98 Aunque debemos indicar que esa lentitud beneficiaba a la comuna, debido a que la larga espera de los barcos estimulaba que los marinos mercantes bajaran a la ciudad vivificando el acontecer de la vida nocturna, implicando en ello la prestación de servicios de hoteles, restaurantes, el comercio establecido, además del mercadeo de los cuerpos prostitucionales. La economía tocopillana se sustentaba también con la considerable población flotante.

99 Galaz-Mandakovic, Damir. 2018. “Alianza obrera, huelga y necropolítica capitalista: Conflicto entre 'los Indios de la Costa' y los 'Yanquis' de la termoeléctrica Guggenheim en Tocopilla (1923)" en Revista Tiempo Histórico № 16, Santiago, pp. 109-135.
} 
presionarían y agitarían sus labores para no perder los trabajos que allí se efectúan (...) sabemos de los perjudiciales boicots efectuados en 1923 cuando los portuarios se unieron a los obreros de la Chile Exploration...y la situación tuvo que ser disuadida con la presencia del Regimiento Esmeralda de Antofagasta" ${ }^{100}$.

Por otra parte, como el ferrocarril electrificado llegó solo hasta la Estación El Tigre y luego articulaba con la Oficina María Elena a través de un ramal cubierto con locomotoras a diésel, con el surgimiento de la Oficina Pedro de Valdivia (1931), las autoridades de Antofagasta (la ciudad más poblada en la costa del desierto de Atacama) realizaron un lobby con Guggenheim Brothers para que la producción de la nueva Oficina fuese exteriorizada por el puerto antofagastino, ya que esta ciudad vivía la crisis económica y social por el desmantelamiento de las minas salitreras del Cantón Central. Finalmente, la línea férrea que iba desde Tocopilla se extendió hasta Pedro de Valdivia, logrando los 116,6 kilómetros y así los deseos de los antofagastinos se vieron truncados por la decisión de la empresa estadounidense ${ }^{101}$.

\section{Conclusiones}

Siguiendo a Schumpeter, podemos decir que el impulso fundamental que pone y mantiene en movimiento a la máquina capitalista procede de los nuevos bienes de consumo, de los nuevos métodos de producción y transporte, de los nuevos mercados, de las nuevas formas de organización industrial que crea la empresa; entonces, el capitalismo es por naturaleza una forma o método de transformación económica, "no estacionaria, sino que no puede serlo nunca" ${ }^{102}$.

El sistema Guggenheim y el nuevo ciclo que inauguró en el desierto minero, podemos caracterizarlo como la expresión de un capitalismo cognitivo ${ }^{103}$. Si bien a lo largo de la historia del capitalismo siempre ha existido una constante preocupación sobre las capacidades de previsión, programación y cálculo sobre los diversos procesos productivos, es siempre la otredad y la exclusividad de ciertos conocimientos lo que permite la reproducción de la acumulación. En el decir de Rullani, el conocimiento se ha puesto al servicio de la producción, cuya tarea es "la de controlar a la naturaleza a través de la técnica y a los hombres a través de la jerarquía” ${ }^{104}$. De ese modo, el conocimiento científico permitió las innovaciones químicas, un

\footnotetext{
${ }^{100}$ AGT, Oficio Confidencial № 12 a la Inspección del trabajo de Tocopilla, 12 diciembre 1931.

${ }^{101}$ Ante el desmantelamiento de las salitreras de EI Toco, la línea férrea originaria, aquella que había sido inaugurada en 1890, fue posteriormente clausurada en 1957, quedando solo vigente el ramal conducente a María Elena y Pedro de Valdivia.

102 Schumpeter, Joseph. 2010. ¿Puede sobrevivir el capitalismo? La destrucción creativa y el futuro de la economía global. Madrid, Ediciones Capitán Swing libros, p.86.

${ }^{103}$ Fumagalli, Andrea. 2010. Bioeconomía e capitalismo cognitivo. Verso un nuovo paradigma di acumulazione. Roma, Carocci Editore.

104 Rullani, E. 2000. “El capitalismo cognitivo: Du déjà vu?”, en Rev. Multitudes, № 2, España, p. 99.
} 
diagnóstico certero sobre los suelos del desierto, las nuevas máquinas, la extensión de los mercados para la circulación de las mercancías y el posterior éxito en los cálculos. Porque finalmente, lo que buscó también el sistema Guggenheim fue el desarrollo de una economía de la velocidad ${ }^{105}$ y también de la fuerza. Ahí estaban las electrificaciones, las mecanizaciones, y las nuevas velocidades en las lixiviaciones, en los ferrocarriles, pero con un terminal portuario que, por efecto de la política y las agencias obreras, operaba como una des-economía ${ }^{106}$ y es ahí la asíntota y el contrapunto de un sistema que no operó parejamente, sino con anacronías y presiones, que finalmente se diluyeron cuando en el caso del sistema portuario de Tocopilla finalmente se electromecanizó en 1961, es decir 35 años después de inaugurado el nuevo ciclo salitrero promovido por Guggenheim Brothers. Fueron 35 años de desfase y heterogeneidad tecnológica en la localidad que energizaba y exteriorizaba la producción minera no metálica, articulando a Tocopilla y a la pampa bajo la impronta estadounidense con cientos de economías mundiales hasta el tiempo presente.

\section{Fuentes y bibliografía}

Archivo Gobernación de Tocopilla (AGT)

Fondo Provincia de Tocopilla.

\section{Diarios}

La Prensa de Tocopilla, Archivo Gobernación de Tocopilla (AGT).

La Nación (Santiago), Archivo Universidad Diego Portales (AUDP).

\section{Bibliografía}

Arce, Isaac. 1997 (1930). Narraciones Históricas de Antofagasta. Antofagasta, Imprenta Moderna.

Arellano-Escudero, Nelson. 2018. "La energía solar industrial en el desierto de Atacama entre 1933 y 1952: investigación, desarrollo y sustentabilidad", en Estudios Atacameños, № 57, San Pedro de Atacama, pp. 119-140.

Arriaza, Bernardo y Galaz-Mandakovic, Damir. 2020. “Expansión minera, déficit hídrico y crisis sanitaria. La potabilización del río Toconce y el impacto del arsenicismo en la población de la Provincia de Antofagasta (1915-1971)", en Historia 396, Vol. 10, №1, Valparaíso, pp. 73-114.

Basciani, Alberto. 2014. "Los Balcanes: el avispero revisitado. Desde la crisis oriental de 1908 a la Primera Guerra Mundial", en Historia y Política № 32, Madrid, pp. 105-127.

Binns, Donald. 1995. The Anglo-Chilean Nitrate and Railway Company. A history of the Company and its locomotives, Yorkshire, Trackside Publications.

Blondeau, Olivier. 2004. Capitalismo cognitivo, propiedad intelectual y creación colectiva, Madrid, Editorial Traficantes de sueños.

\footnotetext{
105 Rullani, E. 2000. “El capitalismo cognitivo: Du déjà vu?”, en Rev. Multitudes, № 2, España, pp. 99-129.

106 Fumagalli, Andrea. 2010. Bioeconomía e capitalismo cognitivo. Verso un nuovo paradigma di acumulazione. Roma, Carocci Editore.
} 
Campdelacreu, Enrique. 2009. (1949) Tocopilla: una memoria de prueba, Tocopilla, Agrupación Cultural y Folclórica Tikopillan.

Collao, Juan. 2001. Historia de Tocopilla (obra póstuma), Tocopilla, Ed. Corporación Juan Collao Cerda. Couyoumdjian, Ricardo. 1986. Chile y la Gran Bretaña durante la primera guerra mundial y la posguerra 1914-1921, Santiago, Editorial Andrés Bello y Ediciones de la Pontificia Universidad Católica de Chile. COVENSA. 1964. Agenda del salitre. Nitrato natural de Chile, Antofagasta, Editorial La Portada.

CSAL (Compañía Salitrera Anglo Lautaro). 1954. Guía general de materias y terminología salitrera, Santiago, Editorial Universo.

CSAL (Compañía Salitrera Anglo Lautaro). 1955. El dilema de la industria salitrera: o se la reestructura de acuerdo con el referéndum de diciembre de 1954. O el salitre desaparece de la economía chilena, Santiago, Editorial Universo.

Csillaj, Ilonka. 2012. Oficinas María Elena y Pedro de Valdivia. El proceso industrial del salitre en el siglo $X X$, Santiago, Fundación Pro Cultura, Santiago.

Cuevas, Enrique. 1930. La industria salitrera y el salitre como abono, Berlín, Ediciones Buchdruckerei Silesia.

Donoso, Carlos. 2014. "El ocaso de la dependencia salitrera (1914-1926)", en Diálogo Andino, № 45, Arica, pp. 97-118.

Finck, Arnold. 1988. Fertilizantes y fertilización: fundamentos y métodos para la fertilización de los cultivos, Barcelona, Editorial Reverté.

Fumagalli, Andrea. 2010. Bioeconomía e capitalismo cognitivo. Verso un nuovo paradigma di acumulazione, Roma, Carocci Editore.

Galaz-Mandakovic, Damir. 2013. Migración y biopolítica. Dos escenas del siglo XX tocopillano, Tocopilla, Retruécanos Ediciones.

Galaz-Mandakovic, Damir. 2017. "Turbinas y electricidad para la mina, lámparas a parafina para la población: crónica de una asimetría del capitalismo minero en Tocopilla (1914-1942)", en Estudios Atacameños № 54, San Pedro de Atacama, pp. 179-200.

Galaz-Mandakovic, Damir. 2018. "Alianza obrera, huelga y necropolítica capitalista: Conflicto entre 'los Indios de la Costa' y los 'Yanquis' de la termoeléctrica Guggenheim en Tocopilla (1923)", en Revista Tiempo Histórico № 16, Santiago, pp. 109-135.

Galaz-Mandakovic, Damir. 2018. "De Guggenheim a Ponce. Sistema técnico, capitalismo y familias en el extenso ciclo de los nitratos en El Toco y Tocopilla (1924-2015)", en Revista Chilena de Antropología № 37, Santiago, pp. 108-130.

Galaz-Mandakovic, Damir. 2019. Movimientos, tensiones y luces. Historias tocopillanas, Tocopilla, Ediciones Bahía Algodonales.

Garcés, Ingrid. (s/f). "Evolución de la tecnología de la industria salitrera: desde la olla del indio hasta nuestros días". Antofagasta, Facultad de Ingeniería Universidad de Antofagasta. Disponible en: https://intranetua.uantof.cl/salitre/Sistema\%20Paradas\%20\%20a\%20Guggenheim.pdf (consultado el 13 de diciembre del 2019).

García, Patricio. 2018. La reinvención de la industria del salitre, Santiago, Ediciones Memoria creativa.

Godoy, Milton. 2019. "Minería, crisis económicas y flujos migratorios en Atacama meridional: Taltal (Chile), 1870-1950", en Revista de Historia, Concepción, 26(2), pp. 5-32.

González Pizarro, José Antonio. 2017. La épica del salitre en el desierto de Atacama, 1880-1967. Trabajo, tecnologías, vida cotidiana, conflicto y cultura, Antofagasta, Ediciones Universitarias, Universidad Católica del Norte.

González, Sergio, Calderón, Renato, Artaza, Pablo. 2016. "El fin del ciclo de expansión del salitre en Chile: la inflexión de 1919 como crisis estructural", en Revista de Historia Industrial, Vol. 25, № 65, Barcelona, pp. 83- 110. 
González, Sergio. 2015. “Normalización de la crisis y posición estratégica empresarial durante la expansión de la economía del salitre", en Polis, Santiago, 14(40), pp. 397-419.

Gutiérrez, Eulogio. 1926. Chuquicamata, Tierra Rojas. Historia y monografía, Santiago, Editorial Nascimento.

Kennedy, Bruce. 1990. Surface Mining. 20 Edition, Baltimore, Couverture, Society for Mining, Metallurgy and Exploration (U.S.).

Latcham, Ricardo. 1926. Chuquicamata. Estado yankee (Visión de la montaña roja), Santiago, Editorial Nascimento.

López, Emiliano. 1926. Los costos en la industria del salitre, Santiago, Imprenta y litografía Universo S.A. Mac Lachlan, Colin y Beezley, Williams. 2010. Mexico's Crucial Century, 1810-1910. An Introduction, United States, University of Nebraska Press.

Macuer, Horacio. 1930. Manual práctico de los trabajos en la pampa salitrera, Valparaíso, Talleres Gráficos Salesianos.

McConnell, Donald. 1935. "The Chilean Nitrate Industry", en The Journal of Political Economy, Vol. 43, № 4, University of Chicago, pp. 506-529.

O'brien, Thomas. 1989. "Rich beyond the Dreams of Avarice: The Guggenheim in Chile", en Business History Review, № 63, Cambridge, pp. 122-159.

Rinke, Stefan. 2002. Cultura de masas: reforma y nacionalismo en Chile 1910-1931, Santiago, Eds. de la Dirección de Bibliotecas, Archivos y Museos, Centro de Investigaciones Diego Barros Arana.

Rodney, Long. 1930. Railways of South America. Part III: Chile, Washington, Governenment printing office.

Rullani, Enzo. 2000. “El capitalismo cognitivo: ¿Du déjà vu?”, en Rev. Multitudes, № 2, España, pp. 99129.

Santos, Boaventura de Sousa. 2009. Una epistemología del sur: la reinvención del conocimiento y la emancipación social, Buenos Aires, Editorial Siglo XXI.

Schumpeter, Joseph. 2010. ¿Puede sobrevivir el capitalismo? La destrucción creativa y el futuro de la economía global, Madrid, Ediciones Capitán Swing libros.

Simondon, Gilbert. 2007. El modo de existencia de los objetos técnicos, Buenos Aires, Editorial Prometeo Libros.

SONAMI (Sociedad Nacional de Minería). 1926. "Los Guggenheim y la industria salitrera", en Boletín Minero de la Sociedad Nacional de Minería № 322, Santiago, pp. 185-190.

SONAMI (Sociedad Nacional de Minería). 1941. "Compañía Salitrera Anglo Chilena (ex Anglo Chilean Consolidate Nitrate Corporation)", en Boletín Minero de la Sociedad Nacional de Minería, № 500, Santiago, pp. 1257-1258.

Soto, Alejandro. 1998. Influencia británica en el salitre. Origen, naturaleza y decadencia, Santiago, Editorial Universidad de Chile.

Thomson, Ian. 2004. "La crisis económica y del salitre de principios del decenio 1930 y su impacto sobre los ferrocarriles", en Eco Pampino, №22, pp.1-6.

United States Department of Agriculture. 1937. Circular № 421. Washington, Government Printing Office.

Whitbeck, Ray. 1931. “Chilean Nitrate and the Nitrogen Revolution”, en Economic Geography, Vol. 7, № 3, pp. 273-283. 